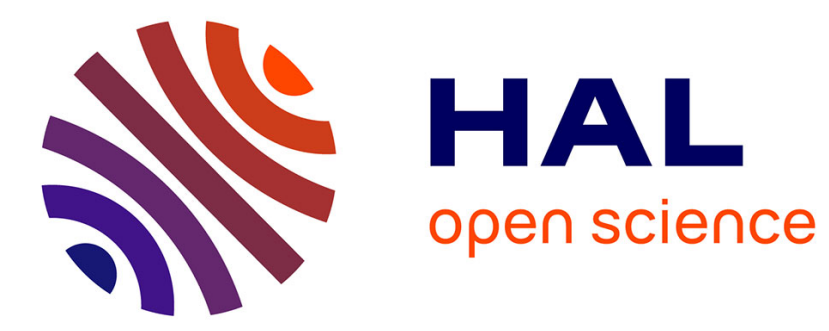

\title{
New route toward nanosized crystalline metal borides with tuneable stoichiometry and variable morphologies
}

Guillaume Gouget, Patricia Beaunier, David Portehault, Clément Sanchez

\section{To cite this version:}

Guillaume Gouget, Patricia Beaunier, David Portehault, Clément Sanchez. New route toward nanosized crystalline metal borides with tuneable stoichiometry and variable morphologies. Faraday Discussions, 2016, 191, pp.511 - 525. 10.1039/C6FD00053C . hal-01440776

\section{HAL Id: hal-01440776 https://hal.sorbonne-universite.fr/hal-01440776}

Submitted on 19 Jan 2017

HAL is a multi-disciplinary open access archive for the deposit and dissemination of scientific research documents, whether they are published or not. The documents may come from teaching and research institutions in France or abroad, or from public or private research centers.
L'archive ouverte pluridisciplinaire HAL, est destinée au dépôt et à la diffusion de documents scientifiques de niveau recherche, publiés ou non, émanant des établissements d'enseignement et de recherche français ou étrangers, des laboratoires publics ou privés. 


\title{
New route toward nanosized crystalline metal borides with tuneable stoichiometry and variable morphologiest
}

\author{
G. Gouget, ${ }^{\mathrm{a}}$ P. Beaunier, ${ }^{\mathrm{b}}$ David Portehault ${ }^{\mathrm{a},{ }^{*}}$ and Clément Sanchez ${ }^{\mathrm{a},{ }^{*}}$
}

Herein we highlight for the first time the ability to tune the stoichiometry of metal boride nanocrystals through nanoparticle synthesis in thermally stable inorganic molten salts. Two metal-boron systems are chosen as case studies: boron-poor nickel borides and boron-rich yttrium borides. We show that NiB, $\mathrm{Ni}_{4} \mathrm{~B}_{3}, \mathrm{Ni}_{2} \mathrm{~B}, \mathrm{Ni}_{3} \mathrm{~B}$, and $\mathrm{YB}_{6}$ particles can be obtained as crystalline phases with good selectivity. Anisotropic crystallization is observed in two cases: the first boron-rich $\mathrm{YB}_{4}$ nanorods are reported, while boron-poor $\mathrm{NiB}$ nanoparticles show a peculiar crystal habit, as they are obtained as spheres with uniaxial defects related to the crystal structure. Crystallization mechanisms are proposed to account for the appearance of these two kinds of anisotropy at the nanoscale.

\section{Introduction}

The family of metal-boron alloys spans a wide range of compounds, including various stoichiometries. This diversity results from the high density of covalent bonds in metal borides structures. By increasing the boron content (Fig. 1), the structure evolves from linear B-B chains, to two- and three-dimensional boron frameworks including interconnected boron clusters ${ }^{1}$ in which B-B lengths are shorter than in onedimensional chains. This structural observation is commonly related to the mechanical properties of metal borides, such as super-hardness in $\mathrm{WB}_{4}{ }^{2}$ or high temperature refractory behavior in metallic ceramics as $\mathrm{HfB}_{2}{ }^{3}$ Covalence also results in high melting temperatures of borides $\left(2600{ }^{\circ} \mathrm{C}\right.$ for $\left.\mathrm{YB}_{6}\right)$ and pure boron allotropes $\left(2075{ }^{\circ} \mathrm{C}\right.$ for $\mathrm{B}$-B). ${ }^{4}$ Noteworthy, the metal-boron interaction also brings specific behaviors. For instance, in OsB, metal atoms bring high electron concentration, so that electrostatic repulsions prevent compression, thus yielding ultra-incompressibility. ${ }^{2}$ More generally, boron-poor

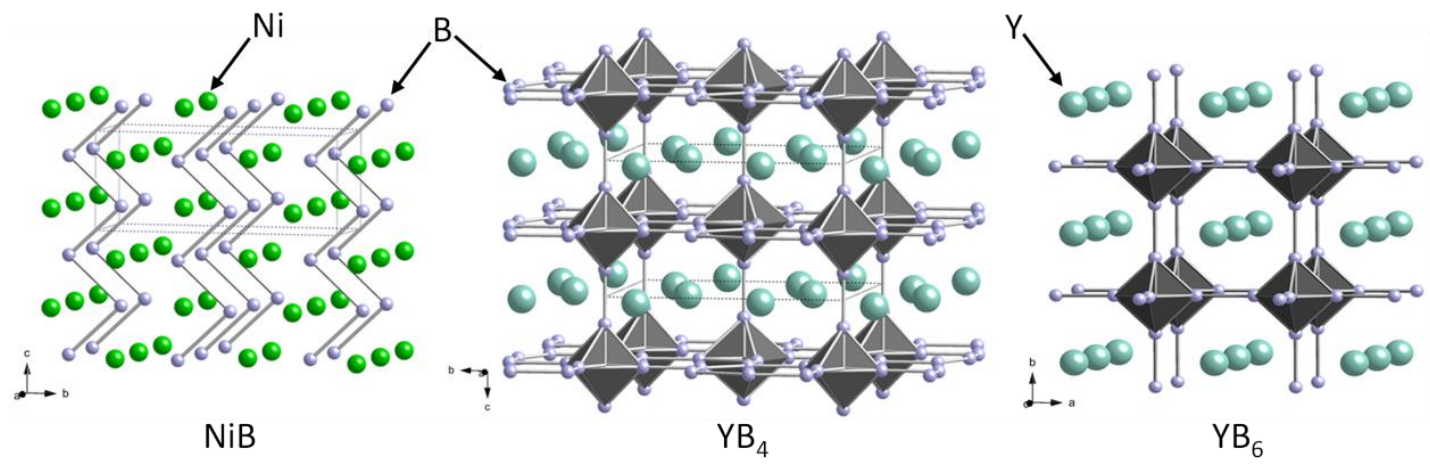

Fig. 1 Crystal structures of $\mathrm{NiB}$ (space group $A m a m), \mathrm{YB}_{4}(P 4 / m b m)$ and $\mathrm{YB}_{6}(P m-3 m)$.

(elemental ratio $M: B \geq 1: 1$ ) borides of transition metals are drawing attention in a range of fields from magnetism ${ }^{5}$ to catalysis. ${ }^{6-9}$ In this latter case, B-poor phases such as $\mathrm{NiB}$ and $\mathrm{CoB}$ are potential low price catalysts for dehydrogenation and Fisher-Tropsch reactions. ${ }^{10}$ In these phases, boron may prevent coking and deactivation of the active sites by sequestering carbon atoms. ${ }^{11,12}$ On the other side, boron-rich borides are actively studied and used, such as hexaborides for field emission ${ }^{13}$ and thermoelectric energy conversion. ${ }^{14}$ Richer borides comprising icosahedral $B_{12}$ boron clusters, for instance $Y_{66}$, are also strongly investigated for thermoelectricy. ${ }^{15}$ Thus, original properties of metal borides are deeply related to both elements and the way they interact. This is particularly exemplified by $\mathrm{MgB}_{2}$ superconductivity ${ }^{16}$ : its remarkably high critical temperature of $39 \mathrm{~K}$ for classical conductors was not expected, given the apparent simplicity of the composition ${ }^{17}$ compared to usual cuprate superconductors. The superconductivity of $\mathrm{MgB}_{2}$ is related to both elements being light, as suggested in the BCS theory, ${ }^{18}$ together with anisotropic boron organisation in metallic honeycomb layers ${ }^{19}$ stabilized by electron transfer from magnesium to boron. All in all, metal borides exhibit a large diversity of technologically 
relevant mechanical and transport behaviours (Fig. 2) that originate from the complex interplay between the covalent boron framework and the metal atoms.

Interestingly, all the above mentioned properties are related to bulk phases. The example of other materials families, including gold ${ }^{20-22}$ and chalcogenides, ${ }^{23}$ shows how properties, e.g. in catalysis and optics, can be impacted when nanoparticles are scrutinized. However, such studies are still extremely scant for crystalline metal borides. ${ }^{5,24}$ Such scarcity originates from the harduous synthesis of crystalline metal borides, which has been discussed recently. ${ }^{24}$ Only few phases are known at the nanoscale, especially rare earth and alkaline earth hexaborides, produced by chemical vapor deposition (CVD) ${ }^{25,26}$, solid state reactions, often under autogeneous pressure. ${ }^{27-29}$ Some transition metal borides $\left(\mathrm{VB}_{2}{ }^{30}, \mathrm{FeB}^{5}\right.$, $\mathrm{CO}_{2} \mathrm{~B}^{31}$ ) have been reported at the nanoscale from solid state chemistry, while $\mathrm{MgB}_{2}$ has been obtained via a range of methods involving the reactivity of gaseous magnesium. ${ }^{32-34}$ In most cases the synthetic processes cannot be generalized to a wide range of metal borides, does not enable size control (except CVD), and particle sizes are rarely below $30 \mathrm{~nm}$, and often above one micrometer. Besides, the control of the final stoichiometry for nanoscaled crystalline metal borides is currently uncharted.

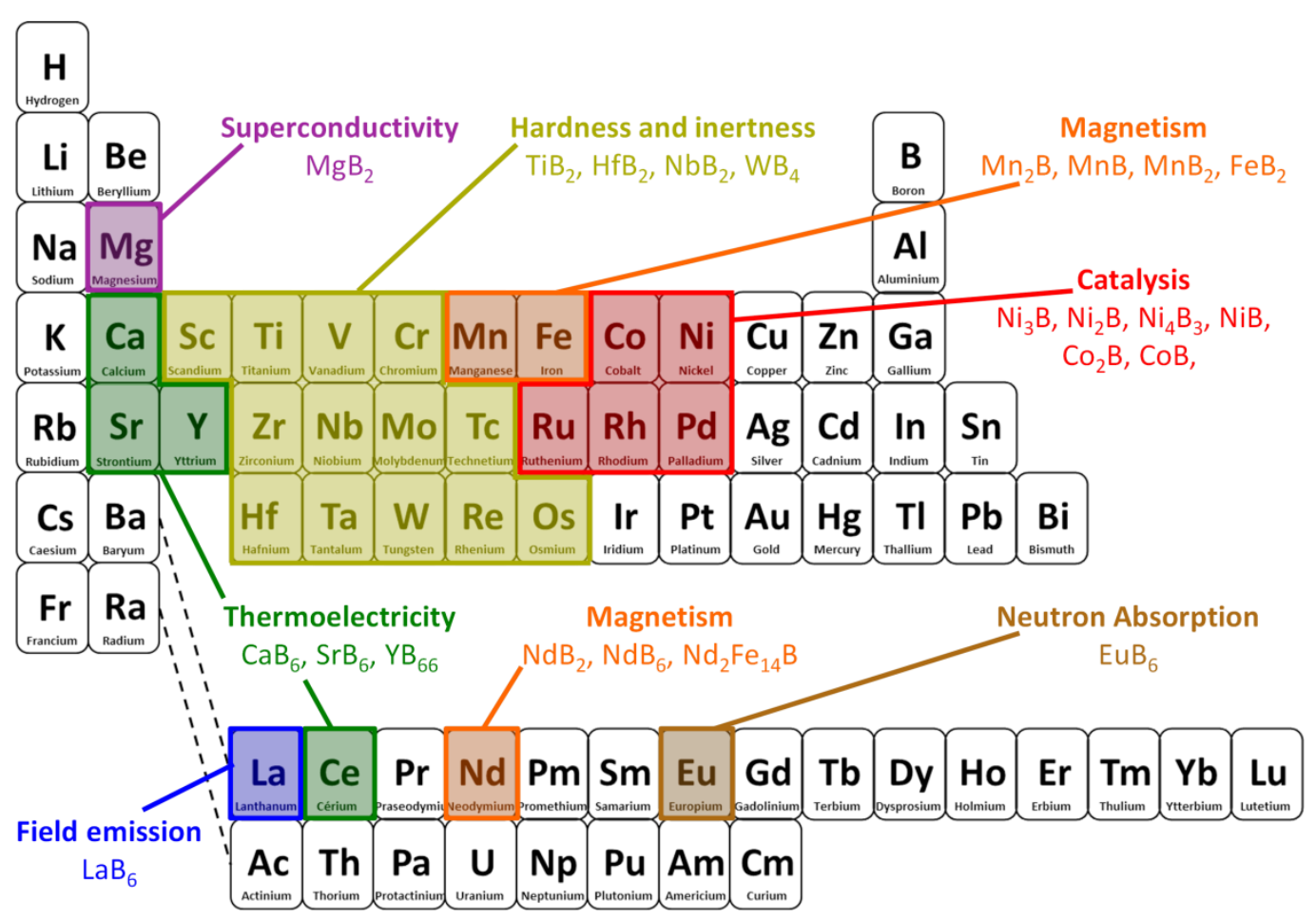

Fig. 2 Attractive properties of metal borides, known for bulk phases. The periodic table of elements is restricted to boron and metals. 


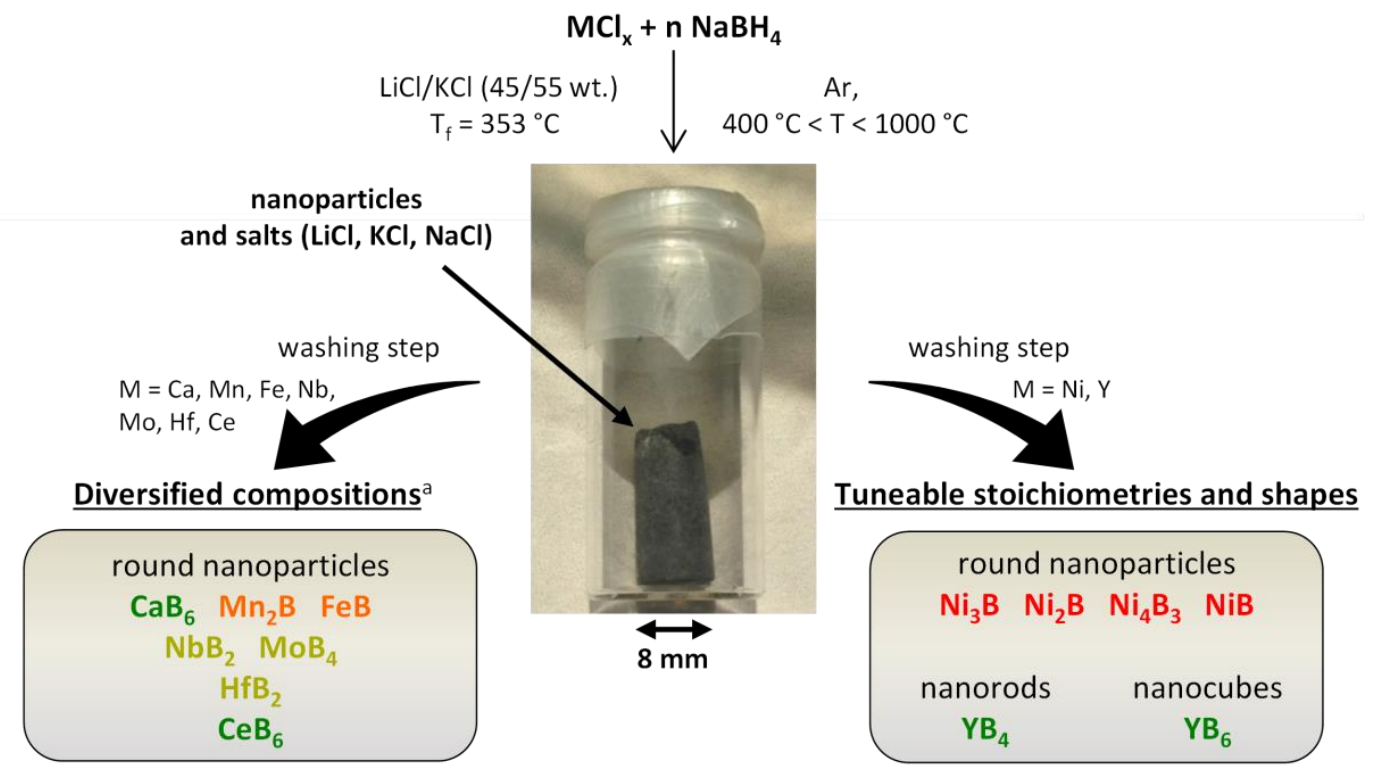

Fig 3. Synthesis of metal borides in inorganic molten salts. $\mathrm{LiCl} / \mathrm{KCl}\left(45 / 55 \mathrm{wt}\right.$.) melts at $\mathrm{T}_{\mathrm{f}}=353^{\circ} \mathrm{C}$. After cooling down the reactant medium and washing out the salts, various metal boride nanoparticles are obtained in term of compositions, stoichiometries and shapes. ${ }^{a}$ Results from Portehault et al. 35.

Recently, a route was proposed toward a wide range of metal boride nanocrystals, ${ }^{35}$ based on the reaction between metal salts and an alkali borohydride below $900^{\circ} \mathrm{C}$, at atmospheric pressure in an inorganic molten salt mixture, composed of $\mathrm{LiCl} / \mathrm{KCl}$ at the eutectic composition $\left(\mathrm{T}_{f}=353^{\circ} \mathrm{C}\right)$. This onepot process enables production of nanocrystalline metal borides at temperatures between $400{ }^{\circ} \mathrm{C}$ and $900{ }^{\circ} \mathrm{C}$, with a readily available, thermally stable and no oxygen-containing solvent, easily eliminated after reaction by using water. In a typical synthesis schematized Fig. 3, the solid precursors and salts are heated together over the melting temperature of the reactant medium in argon atmosphere. After cooling down to room temperature, a black block is obtained. It contains salts that are dissolved afterwards with a polar solvent such as deionized water. Washing and drying the remaining black suspension lead to a black powder consisting of metal boride nanoparticles. The particle size could be controlled and decreased below $20 \mathrm{~nm}$. However, each metal studied was associated to a precise M:B ratio, so that stoichiometry control for a given metal was not provided. Besides, all reported nanoparticles were round shaped.

In this article we present the first evidence of a general synthesis of nanocrystalline metal borides with controlled stoichiometry using syntheses in inorganic molten salts, by focusing on the B-poor Ni-B and Brich $\mathrm{Y}-\mathrm{B}$ systems. Depending on the ratio between metal and boron precursors, the temperature and reaction time, $\mathrm{NiB}, \mathrm{Ni}_{4} \mathrm{~B}_{3}, \mathrm{Ni}_{2} \mathrm{~B}, \mathrm{Ni}_{3} \mathrm{~B}, \mathrm{YB}_{6}$ and $\mathrm{YB}_{4}$ can be selectively fabricated (Fig. 3). Furthermore, we highlight the occurrence of a peculiar anisotropic uniaxial defective crystal structure within spherical particles that originate from crystallization in confined space. Finally, we report for the first time the ability to reach anisotropic nanoparticles, as a first step toward morphological control of crystalline metal boride nanostructures.

\section{Results}

Briefly, all syntheses were performed under inert argon atmosphere. Prior to heating, metal chlorides and sodium borohydride were mixed under argon with the powder mixture of $\mathrm{LiCl}$ and $\mathrm{KCl}$ at the eutectic composition (45/55 wt.). After reaction and cooling, the frozen salt matrix was washed with deionized water, the remaining black powders were dried under vacuum and stored in air. 


\section{Nickel borides}

Starting from $\mathrm{NiCl}_{2}$ as metal precursor, the reaction medium was heated at $750{ }^{\circ} \mathrm{C}$ during $1.5 \mathrm{~h}$. Different $\mathrm{NiCl}_{2}: \mathrm{NaBH}_{4}$ (Ni:B) molar ratios were investigated. The corresponding X-Ray diffraction (XRD) patterns (Fig. 4) show that for $\mathrm{Ni}: \mathrm{B}=1: 2, \mathrm{NiB}$ is the major product, with broad reflections suggesting nanosized crystallites. The apparent crystallite size calculated according to the Scherrer formula is $9 \pm 2 \mathrm{~nm}$. Minor peaks of $\mathrm{Ni}_{4} \mathrm{~B}_{3}$ are also observed. For $\mathrm{Ni}: \mathrm{B}=1: 1.2 ; 1: 1$ and $0.65, \mathrm{Ni}_{4} \mathrm{~B}_{3}, \mathrm{Ni}_{2} \mathrm{~B}$ and $\mathrm{Ni}_{3} \mathrm{~B}$ are isolated as single crystalline phases, respectively. Minor parasite peaks are observed in the two last patterns. They could not be indexed along with a known phase. In contrast to $\mathrm{NiB}, \mathrm{Ni}_{4} \mathrm{~B}_{3}, \mathrm{Ni}_{2} \mathrm{~B}$ and $\mathrm{Ni}_{3} \mathrm{~B}$ patterns show narrow peaks that suggest larger particles. The calculated crystallite sizes for $\mathrm{Ni}_{4} \mathrm{~B}_{3}, \mathrm{Ni}_{2} \mathrm{~B}$ and $\mathrm{Ni}_{3} \mathrm{~B}$ are $29 \pm 6,33 \pm 3$ and $40 \pm 2 \mathrm{~nm}$, respectively.

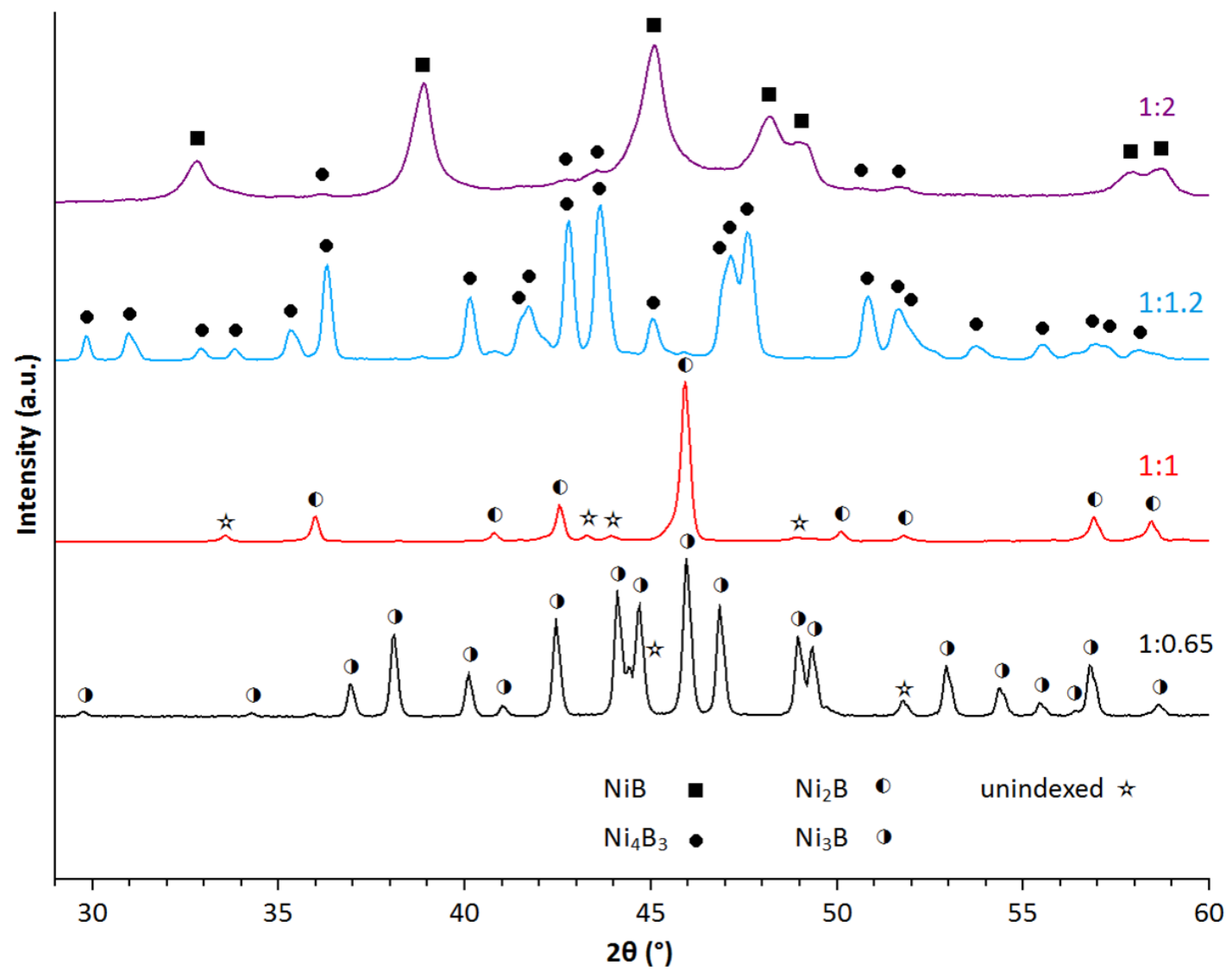

Fig. 4 Powder XRD patterns for $\mathrm{NiCl}_{2}: \mathrm{NaBH}_{4}$ molar ratios 1:2, 1:1.2, 1:1 and 1:0.65.

Transmission electron microscopy (TEM) of the $\mathrm{NiB}\left(\mathrm{NiCl}_{2}: \mathrm{NaBH}_{4}=1: 2\right)$ sample (Fig. S1) reveals spherical crystalline nanoparticles of 2 to $40 \mathrm{~nm}$, in agreement with the crystallite size, dispersed within an amorphous matrix of 1 to $2 \mathrm{~nm}$ thickness. The smaller the particles, the more they tend to perfect spheres. Particles bigger than $20 \mathrm{~nm}$ are slightly faceted. High resolution TEM (HRTEM) (Fig. 5) highlights lattice fringes in a spherical $\mathrm{NiB}$ nanoparticle. Many defects are observed and demonstrate the polycrystalline nature of each particle. Noteworthy single crystalline domains appear as parallel stripes within the single isotropic particles. When comparing two domains aside, the orientation of B-B bonds changes. For instance (Fig. $5 c$ and e) the two domains with [0-12] and [-1-12] zone axes differ from each other by rotating the structure $17.2^{\circ}$ along the [021]* direction. Note that such a defect does not yield coherent domains, as the zig-zag chains are discontinued at the interface (Fig. $5 \mathrm{~d}$ ). Each single domain can be indexed according to the NiB structure for all particles with diameter below $20 \mathrm{~nm}$ (Fig. S2). A minority of bigger faceted particles are indexed as $\mathrm{Ni}_{4} \mathrm{~B}_{3}$ (Fig. S3). Brunauer-Emmett-Teller analysis of the $\mathrm{N}_{2}$ sorption isotherms provides a specific surface area value of $57 \mathrm{~m}^{2} \cdot \mathrm{g}^{-1}$ for the $\mathrm{NiB}$ sample $\left(\mathrm{NiCl}_{2}: \mathrm{NaBH}_{4}=\right.$ 
1:2), almost three times higher than values reported for analog amorphous ${ }^{6}$ or crystalline $^{36} \mathrm{NiB}$ nanoparticles $\left(20 \mathrm{~m}^{2} \cdot \mathrm{g}^{-1}\right)$.

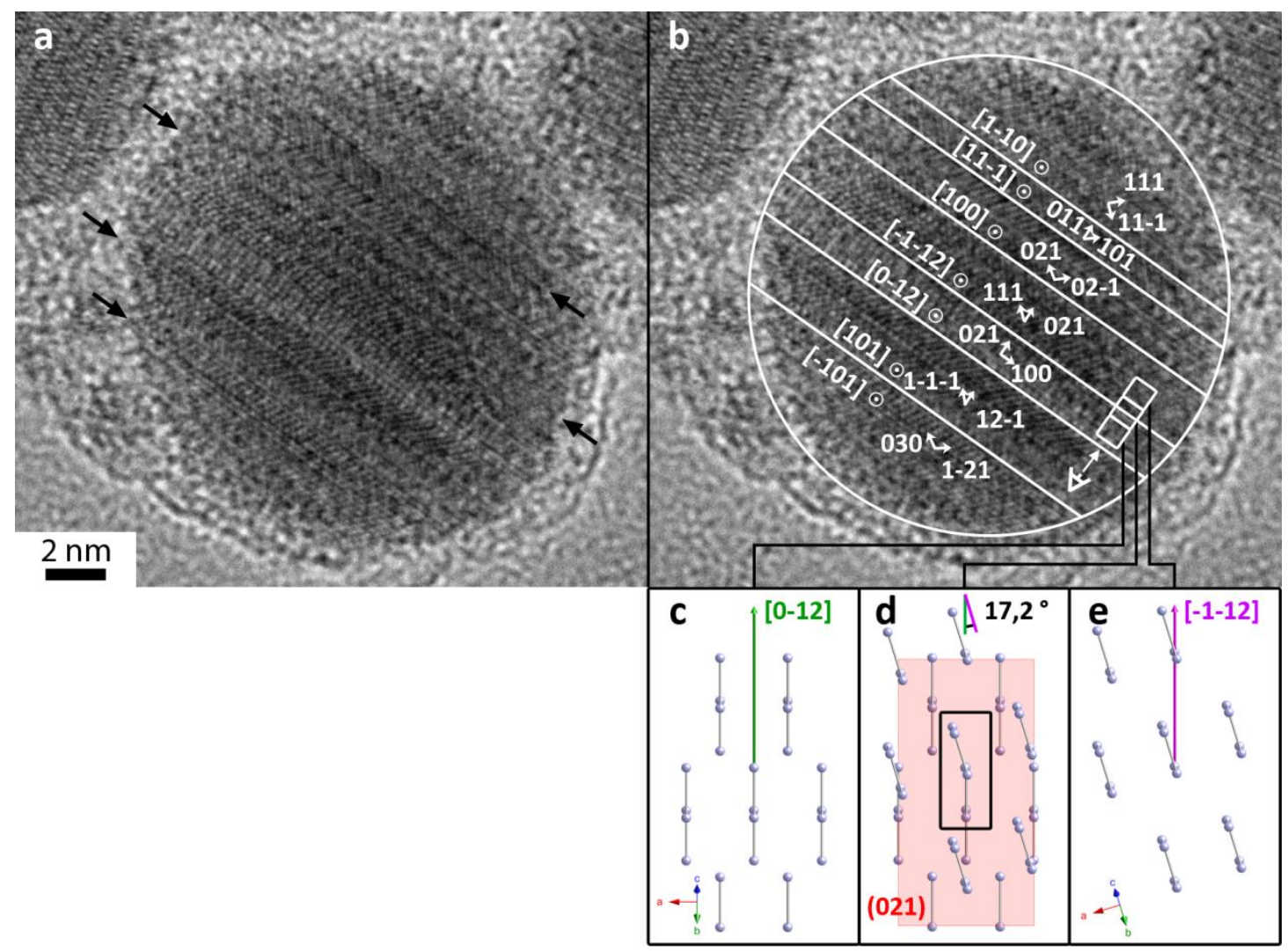

Fig. 5 HRTEM picture of a NiB nanoparticle from the initial ratio $\mathrm{NiCl}_{2}: \mathrm{NaBH}_{4}=1: 2$ and orientations of $\mathrm{B}-\mathrm{B}$ bonds for two consecutive single crystal domains. a) Black arrows highlight the direction of uniaxial defects within the crystalline NiB particle. b) For each single domain stripe, the zone axes and lattice planes are indexed according to the NiB structure. c-e) Example of a misfit at the interface between two domains, viewed orthogonally to the (021) interface: c) ahead the interface, d) at the interface and e) behind of the interface. Nickel atoms are omitted for clarity.

Fig. S4 displays TEM and HRTEM pictures of the samples obtained for higher proportions of sodium borohydride. In agreement with XRD results, $50-200 \mathrm{~nm}$ crystals of $\mathrm{Ni}_{4} \mathrm{~B}_{3}$ and $\mathrm{Ni}_{2} \mathrm{~B}$ embedded in an amorphous layer ( 1 to $2 \mathrm{~nm}$ thick) are observed for initial $\mathrm{NiCl}_{2}: \mathrm{NaBH}_{4}$ ratios 1:1.2 and 1:1. The sample with a $\mathrm{NiCl}_{2}: \mathrm{NaBH}_{4}$ ratio of 1:0.65 is made of particles bigger than $100 \mathrm{~nm}$ (Fig. S5).

SEM-EDX analyses show that all samples are composed of boron, nickel, and oxygen. For $\mathrm{NiCl}_{2}: \mathrm{NaBH}_{4}=1: 2$, quantitative analysis provides an elemental composition $\mathrm{B}_{58} \mathrm{Ni}_{31} \mathrm{O}_{11}$. We showed previously that the amorphous matrix embedding the particles is partially oxidized boron. ${ }^{35}$ Consequently, by considering that the crystalline phase is in the vast majority $\mathrm{NiB}$, then the material composition is equivalent to $(\mathrm{NiB})_{31}\left(B_{27} \mathrm{O}_{11}\right)$, reflecting the biphasic crystalline-NiB/amorphous- $\mathrm{B}\left(\mathrm{B}_{\mathrm{am}}\right)$ character of the sample. $54 \%$ of the $B$ atoms are involved in the crystalline phase, in accordance with the initial excess of boron introduced. The $O / B$ content within the amorphous phase is $O / B_{a m}=0.4$, which suggests that the amorphous layer is composed of partially oxidized amorphous boron, in agreement with previous reports. Unfortunately, the boron content could not be quantitatively evaluated by SEMEDX in the samples from initial $\mathrm{NiCl}_{2}: \mathrm{NaBH}_{4}$ ratios $1: 1.2,1: 1$ and 1:0.65 as the $\mathrm{B}$ content was too low to unambiguously deconvolute the EDX peaks of B and C Ka edges (Fig. S6). 


\section{Yttrium borides}

By using $\mathrm{YCl}_{3}$ as metal precursor, yttrium borides can be targeted through synthesis in molten salts. In order to reach different boron-rich compounds, extensive screening of experimental parameters was performed, by focusing on the yttrium-to-boron precursor ratio $\mathrm{YCl}_{3}: \mathrm{NaBH}_{4}$, as in the $\mathrm{Ni}-\mathrm{B}$ system, but also on the temperature and the dwell time. Below, the different samples are identified as " $\mathrm{YCl}_{3}: \mathrm{NaBH}_{4}-T$ $t^{\prime \prime}$, where $T$ and $t$ are respectively the reaction temperature $\left({ }^{\circ} \mathrm{C}\right)$ and duration $(\mathrm{h})$. By screening these conditions, speciation diagrams can be mapped (Fig. 6), where relative amounts of crystalline phases are qualitatively evaluated from the relative intensities of the corresponding phases in the XRD patterns. Overall and as expected, $\mathrm{YB}_{6}$ is favored at high proportions of $\mathrm{NaBH}_{4}$, but also at high $T$ and $t$.

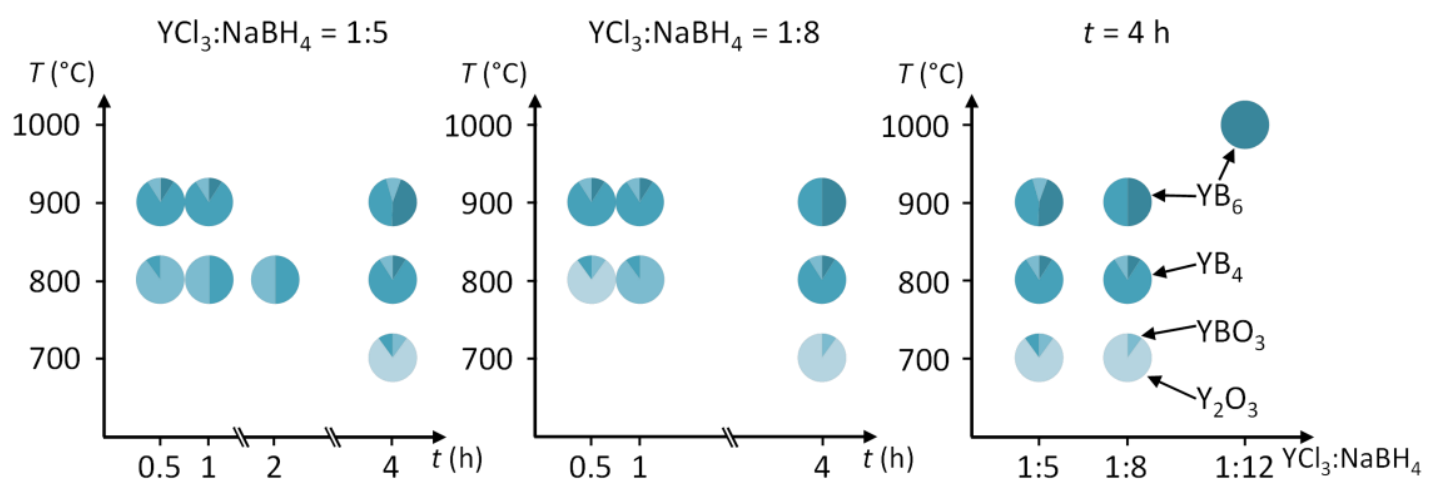

Fig. 6 Speciation diagrams of yttrium borides and other yttrium phases obtained by synthesis in salt melts in respect to the molar ratio of precursors $\left(\mathrm{YCl}_{3}: \mathrm{NaBH}_{4}\right)$, the temperature $(T)$ and the time $(t)$ of heat treatment. Left to right: $\mathrm{YCl}_{3}: \mathrm{NaBH}_{4}$ is fixed at 1:5, $T$ and $t$ vary; $\mathrm{YCl}_{3}: \mathrm{NaBH}_{4}=1: 8, T$ and $t$ vary; and $t=4 \mathrm{~h}, \mathrm{YCl}_{3}: \mathrm{NaBH}_{4}$ and $T$ vary. For each experiment, the phase proportion is qualitatively represented in a histogram pie.

The XRD diagrams of three typical powders are displayed Fig. 7. The sample 1:12-1000-4 exhibits the cubic structure of $\mathrm{YB}_{6}$ as the only crystalline phase. For 1:8-900-4, the reflections are attributed to $\mathrm{YB}_{4}$ and $Y_{6}$. For 1:5-800-1, two crystalline phases are observed: $\mathrm{YB}_{4}$ is the only metal boride phase, while the yttrium borate $\mathrm{Y}\left(\mathrm{BO}_{3}\right)$ is also observed. More generally, at low temperature and short time corresponding to a low energy input, oxidized phases (yttrium borate or oxide $\mathrm{Y}_{2} \mathrm{O}_{3}$ ) are obtained. As the reaction media do not contain any source of oxygen, then these byproducts originate from poorly stable yttrium species that react with water during the washing step. Efforts to selectively dissolve this oxidized phase, using acidic or reductive conditions, were inefficient. 


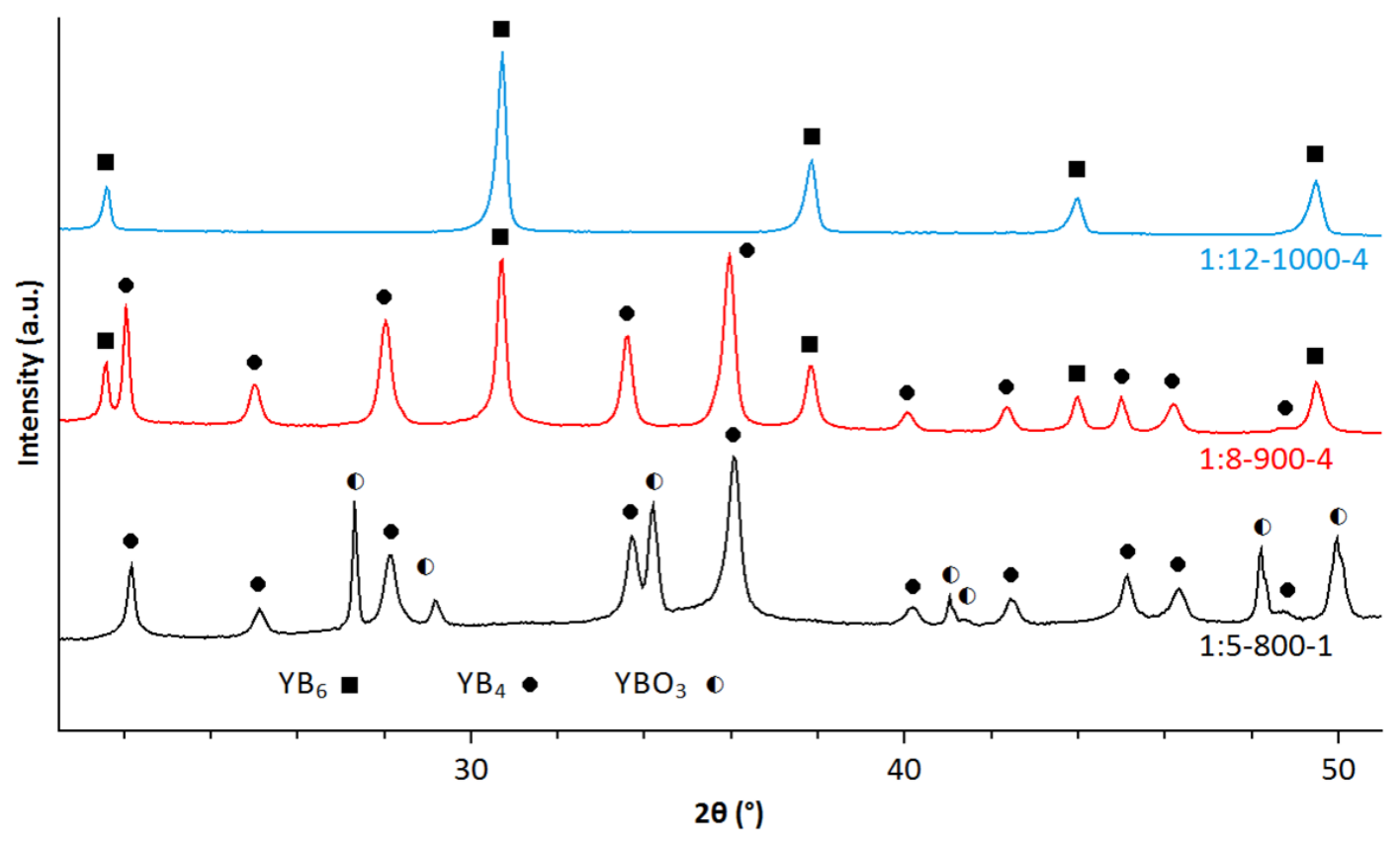

Fig. 7 XRD patterns of yttrium boride samples a) 1:12-1000-4 (YB 6 , b) 1:8-900-4 $\left(\mathrm{YB}_{4}\right.$ and $\left.\mathrm{YB}_{6}\right)$ and c) 1:5800-1 ( $\mathrm{YB}_{4}$ and $\left.\mathrm{YBO}_{3}\right)$.

Apparent crystallite sizes $\varepsilon_{h k l}$ were calculated for the different crystalline phases (Table 1). Smaller $\mathrm{YB}_{6}$ particles are synthetized at $1000{ }^{\circ} \mathrm{C}\left(\varepsilon_{h k l}=49 \mathrm{~nm}\right.$ for $\left.\mathrm{YCl}_{3}: \mathrm{NaBH}_{4}=1: 12\right)$ than $900{ }^{\circ} \mathrm{C}\left(\varepsilon_{h k l}=59 \mathrm{~nm}\right.$ for $\mathrm{YCl}_{3}: \mathrm{NaBH}_{4}=1: 8$ ). In other common systems, an increase in the temperature usually yields extensive growth and bigger particles, thus suggesting in the specific case of this boride synthesis in molten salts that the initial reagent ratio (e.g. $\left.\mathrm{YCl}_{3}: \mathrm{NaBH}_{4}\right)$ is the key parameter for size control. For $\mathrm{YB}_{4}(1: 8-900-4$ sample), anisotropic crystallites are detected, with $\varepsilon_{00 l}=81 \mathrm{~nm}$ and $\varepsilon_{h k o}=26 \mathrm{~nm}$, thus indicating faster growth along the [001] axis.

Table 1 Apparent crystallite sizes of yttrium borides calculated from the XRD diagrams.

\begin{tabular}{lcccc}
\hline Sample & $\mathrm{YB}_{6}$ & & $\mathrm{YB}_{4}$ & \\
& $\varepsilon_{h k l}(\mathrm{~nm})$ & $\varepsilon_{\text {ool }}(\mathrm{nm})$ & $\varepsilon_{h k 0}(\mathrm{~nm})$ \\
\hline $1: 12-1000-4$ & 49 & - & - \\
$1: 8-900-4$ & 59 & 81 & 26 \\
$1: 5-800-1$ & - & 51 & 18 \\
\hline
\end{tabular}

TEM observation of the 1:12-1000-4 sample (Fig. 8a-c) highlights cubic particles with diameters ranging from 30 to $200 \mathrm{~nm}$. The selected area electron diffraction (SAED) pattern (Fig. 8a inset) on an ensemble of particles shows that the particles are $\mathrm{YB}_{6}$ cubes, in agreement with XRD. HRTEM (Fig. 8d) of one nanocube highlights $0.41 \mathrm{~nm}(100)$ lattice fringes showing that the nanocubes expose (100) faces, which is consistent with the cubic structure of metal hexaborides (Fig. 1) and with previous reports on bigger hexaboride particles. ${ }^{27} \mathrm{~A}$ thin amorphous layer is distinguished at the surface of the crystals, with thickness below $1 \mathrm{~nm}$. Note that although the cubes are well faceted, they exhibit rough surfaces and round angles (Fig. $8 \mathrm{~b}$ and c). Slight amounts of amorphous matter are also observed next to the cubes (Fig. 8b and c). 


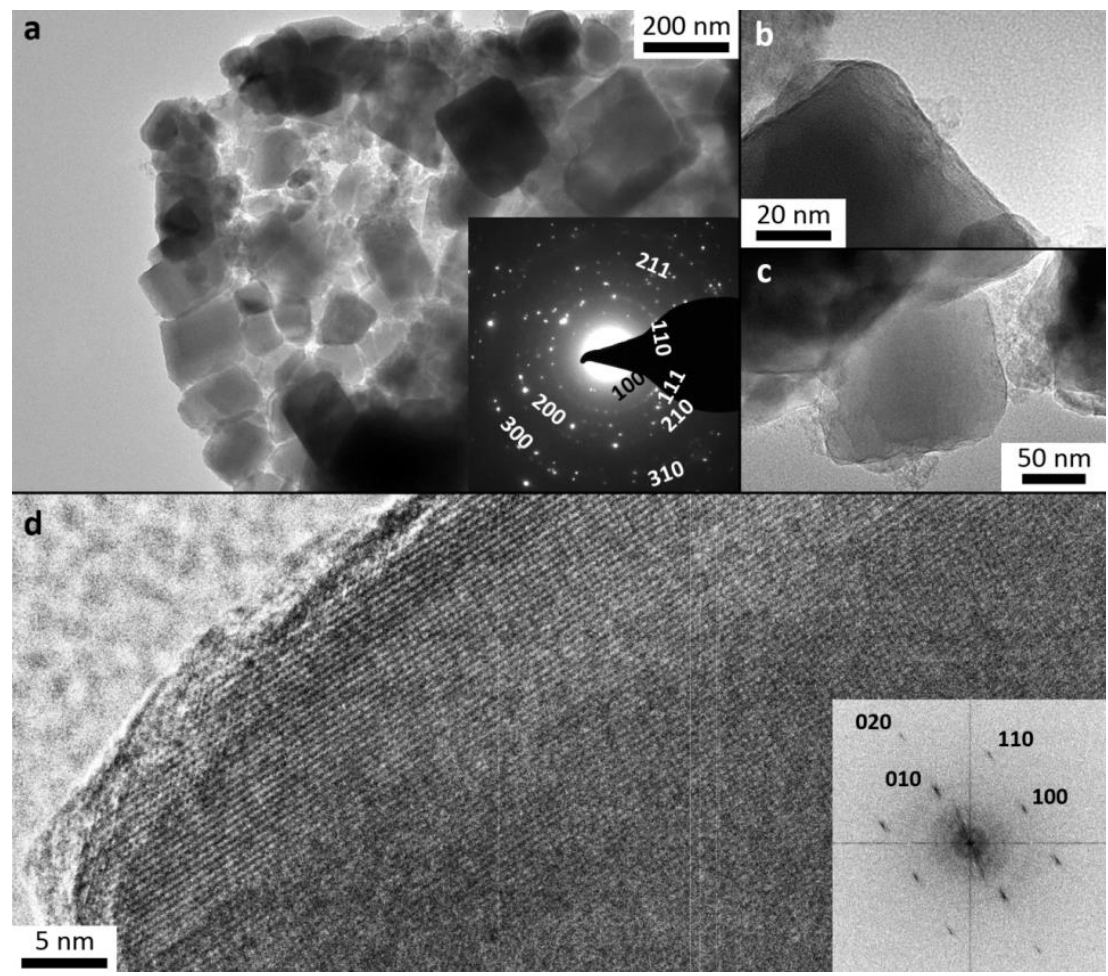

Fig. 8 TEM analysis of $\mathrm{YB}_{6}$ particles (1:12-1000-4 sample). a-c) Low magnification images of a region exhibiting nanocubes, the SAED pattern in the inset is indexed along the $\mathrm{YB}_{6}$ structure. d) HRTEM picture of a nanocube and the corresponding Fast Fourier Transform in inset.

TEM on the 1:8-900-4 sample (Fig. 9a and c) displays two populations of crystalline particles, consisting in approximately $100 \mathrm{~nm}$ long and $30 \mathrm{~nm}$ large nanorods on one side, and $80 \mathrm{~nm}$ nanocubes on the other side. All crystals are embedded in a nanotextured amorphous solid, already encountered for $\mathrm{Ni}-\mathrm{B}$ systems, that is made of partially oxidized boron. Again, the nanocubes are $\mathrm{YB}_{6}$ (Fig. 9e) particles. On the contrary, HRTEM (Fig. 9b) performed on the tip of one nanorod shows lattice distances of $0.50 \mathrm{~nm}$ and $0.40 \mathrm{~nm}$, which correspond to (110) and (001) planes of $\mathrm{YB}_{4}$, respectively. Consequently, these $\mathrm{YB}_{4}$ nanorods exhibit preferential growth along the [001] axis, in accordance with XRD results. To our knowledge, we report here the first occurrence of a metal tetraboride at the nanoscale with well-defined morphology. 


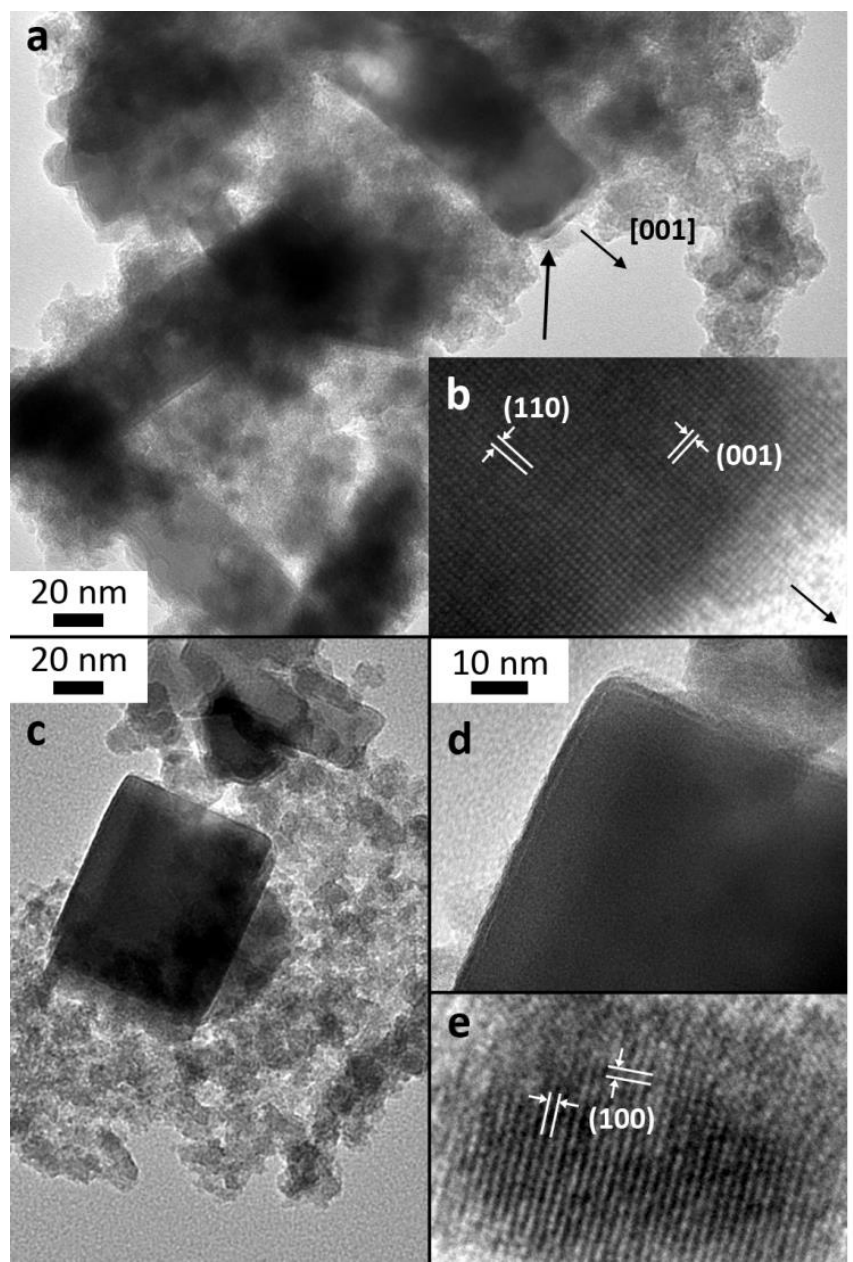

\section{YB4 nanorods}

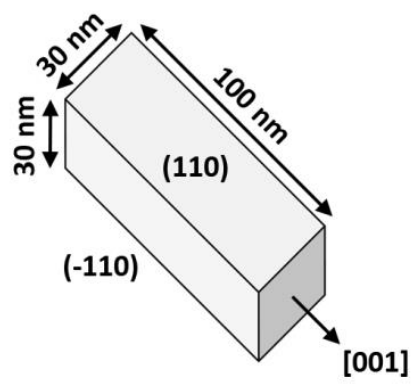

YB6 nanocubes

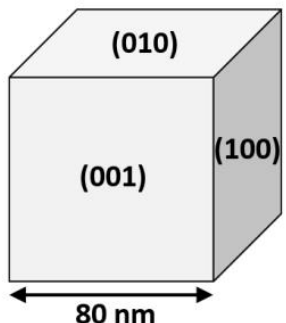

$80 \mathrm{~nm}$

Fig. 9 Left: TEM analysis of the 1:8-900-4 sample. a) Low magnification picture of a region exhibiting nanorods dispersed in an amorphous oxidized boron matrix, b) HRTEM picture of a nanorod with fringes corresponding to $\mathrm{YB}_{4}, \mathrm{c}$ ) and d) TEM pictures of a region exhibiting a nanocube partially embedded in an amorphous oxidized boron matrix and e) HRTEM picture of a nanocube indexed along the $\mathrm{YB}_{6}$ structure. Right: typical morphologies of yttrium borides observed in the 1:8-900-4 sample.

\section{Discussion}

\section{Composition selectivity in the crystalline phase}

For a given metal-boron binary system, the results presented herein indicate the feasibility to control the stoichiometry of crystalline nanoparticles by using a set of synthesis parameters, such as the ratio of metal and boron precursors, the temperature and the heating duration. This composition control is first shown for the Bpoor nickel borides, with $\mathrm{NiB}$ nanospheres of 2 to $20 \mathrm{~nm}$ diameter $\left(\mathrm{NiCl}_{2}: \mathrm{NaBH}_{4}=1: 2\right)$. This is, to our knowledge, the smallest crystalline nickel boride nanoparticles synthesized so far. ${ }^{36} \mathrm{Ni}_{4} \mathrm{~B}_{3}, \mathrm{Ni}_{2} \mathrm{~B}$ and $\mathrm{Ni}_{3} \mathrm{~B}$ can also be selectively fabricated by only varying the precursor $\mathrm{NiCl}_{2}: \mathrm{NaBH}_{4}$ ratio from 1:1.2, 1:1 and 1:0.65 ratios, respectively. In these latter cases, particles are bigger than for $\mathrm{NiB}$ but are still below $100 \mathrm{~nm}$. To our knowledge, we show here the first occurences of $\mathrm{Ni}_{4} \mathrm{~B}_{3}$ and $\mathrm{Ni}_{2} \mathrm{~B}$ nanocrystals with such a small size, while crystalline $\mathrm{Ni}_{3} \mathrm{~B}$ particles were previously reported. ${ }^{36}$ On the side of $\mathrm{B}$-rich phases, we explored the yttrium-boron system. $\mathrm{YB}_{6}$ nanocubes of $c a .80 \mathrm{~nm}$ are reachable, while $\mathrm{YB}_{4}$ nanorods are synthesized for the first time. In this latter case, oxidized phases, especially yttrium borate $\mathrm{YBO}_{3}$, are observed as side product and suggest that the powder prior to washing exhibits reactive yttrium species, presumably poorly crystalline solid phases that oxidize spontaneously in contact with air and water. Although more efforts are required to isolate single crystalline phases in the case of yttrium, the $\mathrm{Ni}-\mathrm{B}$ and Y-B systems clearly demonstrate that increasing the relative amount of borohydride precursor favors the synthesis of higher borides, as expected intuitively. In addition, a temperature increase drives the reaction 
towards B-rich phases, in agreement with the high energy barrier to crystallization exhibited by such compounds that usually require synthesis at high temperature, above $1000{ }^{\circ} \mathrm{C}$ in solid state reactions. ${ }^{37}$

Noteworthy, an amorphous phase made of partially oxidized boron ${ }^{35}$ is always observed, whether as a 1 to $2 \mathrm{~nm}$-thick shell (Fig. 5 and 8 d) or as particles separated (Fig. 8 and 9) from the crystalline phases. As oxidation can only occur during the washing step, then amorphous boron is obtained at the end of the synthesis, prior to purification. The occurrence of this amorphous component is consistent with the fact that an excess of boron precursor is always required to reach a given metal-to-boron ratio in the crystalline phase (e.g. $\mathrm{NiCl}_{2}: \mathrm{NaBH}_{4}=1: 2$ for $\mathrm{NiB}, \mathrm{YCl}_{3}: \mathrm{NaBH}_{4}=1: 12$ for $\left.\mathrm{YB}_{6}\right)$. Hence, part of the boron atoms initially introduced is segregated into the amorphous shell in the final product. Consequently, we hypothesize that this amorphous phase is reminiscent of the growth mechanism, which will be discussed elsewhere. Nevertheless, this amorphous shell has been shown ${ }^{35}$ to be sufficiently porous to provide access of ionic species to the surface of the nanocrystals, so that it enables future investigation of catalytic properties.

\section{Crystal habit: faceting and occurrence of anisotropy in metal boride nanocrystals}

Particle size control. As exemplified previously on $\mathrm{NbB}_{2}$ nanocrystals, ${ }^{35}$ an increase of the metal-to-boron ratio in the precursor ratio yields a decrease in the size of crystalline $\mathrm{YB}_{6}$ nanoparticles. Two explanations can be proposed to account for this size reduction. First, as the concentration of metal precursor is constant, then an increase in the relative amount of borohydride results in an overall increase in the reactant concentrations, thus favoring nucleation over growth and yielding smaller particles. A second explanation may originate from the amorphous boron shell formed in the course of the reaction. Indeed, an increase of the borohydride content should yield an increase in the volume fraction of the amorphous boron phase, which may act as a template restricting nanocrystal growth.

Anisotropic shapes: the case of yttrium boride $\mathrm{YB}_{4}$. Isotropic $\mathrm{YB}_{6}$ nanocubes could be obtained from the synthesis in molten salts at ambient pressure. These particles are similar to other hexaboride particles as previously reported from solid-state methods under autogeneous pressure. ${ }^{27}$ They exhibit $\{100\}$ facets and a morphology related to the cubic symmetry of the crystal structure of hexaborides. More interestingly, $\mathrm{YB}_{4}$ nanocrystals could be observed for the first time. Moreover they exhibit a nanorod shape with an anisotropy factor of $c a$. 3. Noteworthy, the only processes reported so far to produce anisotropic one-dimensional (1D) nanostructures of metal borides employed reactive gaseous species, for instance through chemical or physical vapor deposition. ${ }^{24}$ They were mostly focused on metal hexaborides. Herein, we report the first example of 1D crystalline metal boride nanoparticles from a liquid synthesis. Contrary to reactions based on gaseous species and that often yield $1 \mathrm{D}$ nano-objects through the mediation of a substrate, the $\mathrm{YB}_{4}$ are likely to grow through a specific crystal habit related to the crystal structure of $\mathrm{YB}_{4}$. Indeed, its tetragonal structure differentiates the (001) plane on one side and the (hk0) planes on the other side. More in-depth observation of the reported crystal structure (Fig. 1 and 10) shows that chains of $B_{6}$ octahedra clusters run along the $c$ axis (orthogonal to the (001) plane), while the $(a, b)$ plane can be considered as sheets of $B_{6}$ clusters connected by $B_{2}$ dumbbells. The $Y$ atoms are located between the $B_{6}$ sheets, on top of the holes left within the sheets between $B_{6}$ clusters and $B_{2}$ dumbbells (Fig. 10). The nanorods show $\{001\}$ tip facets and $\{110\}$ lateral faces. Interestingly, the B-terminated $\{110\}$ planes show the highest densities of $B_{6}$ clusters and $B$ atoms $\left(0.05 B_{6}\right.$ clusters $\cdot \mathrm{nm}^{-2}$ and $0.35 B$ atoms $\left.\cdot \mathrm{nm}^{-2}\right)$ in $Y_{4}$, while $\{001\}$ and $\{100\}$ planes show the second $\left(0.04 B_{6}\right.$ clusters $\cdot \mathrm{nm}^{-2}$ and $0.32 \mathrm{~B}$ atoms $\left.\cdot \mathrm{nm}^{-2}\right)$ and third $\left(0.03 \mathrm{~B}_{6}\right.$ clusters $\cdot \mathrm{nm}^{-2}$ and $0.28 \mathrm{~B}$ atoms $\cdot \mathrm{nm}^{-2}$ ) highest $\mathrm{B}_{6}$ and $B$ densities, respectively. Consequently, one can draw a parallel with the crystal habit of more common compounds such as oxides, for which growth directions in classical crystallization are often driven by surface energies (Wulff Law), ${ }^{38}$ in turn related (in the absence of surface directing ligand) to the atom density in each plane. Indeed, the most stable faces are usually those showing the highest atom densities. The correlation of the $B_{6}$ and $B$ density with the relative amount of the different facets in $\mathrm{YB}_{4}$ nanorods ( $\{110\}$ in majority, $\{001\}$ (tips) in minority, while no $\{100\}$ face is observed) indicates that the surface energy is driven by the density of $B_{6}$ clusters or $B$ atoms, as building-blocks of the $\mathrm{YB}_{4}$ structure. B-terminated facets are indeed expected from the excess of boron source introduced. Although the consideration of relative surface energies requires confirmation by first principle calculations, it is consistent with the high strength of the $B-B$ bonds in such compounds and with the high stability of $B_{6}$ clusters in borides, ${ }^{39}$ which suggest that the boron covalent framework should drive the relative surface energies, so that the role of the metal atoms would be 
secondary. Noteworthy, the largest facets in bulk tetraboride grown by a metal flux method are also $\{110\},{ }^{40}$ confirming their low surface energy.

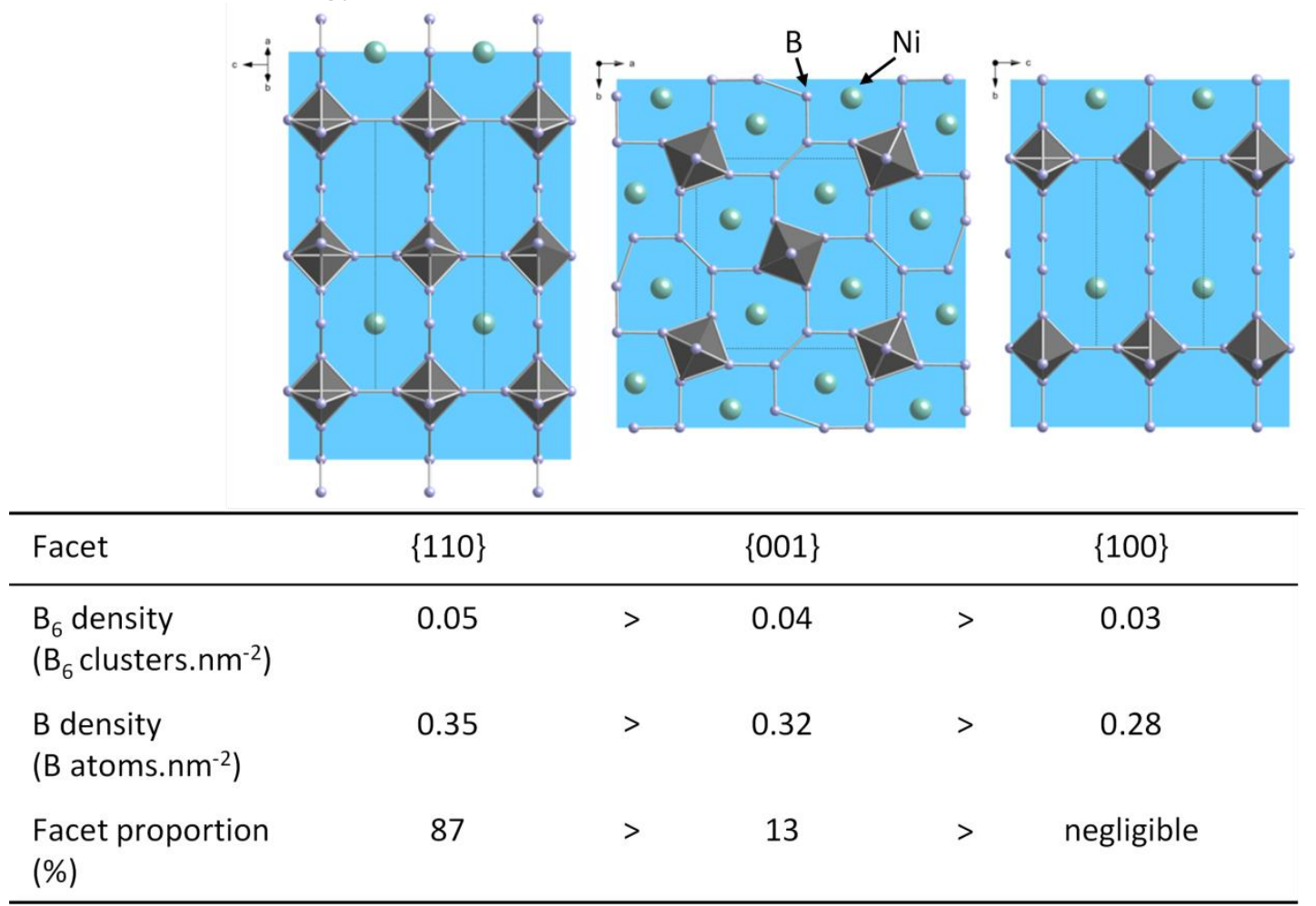

Fig. 10 Facets $\{110\},\{001\}$ and $\{100\}$ of yttrium tetraboride and density of boron octahedra and boron atoms for the three facets. The facet proportion in $\mathrm{YB}_{4}$ nanorods is evaluated according to dimensions observed Fig. 9. It increases with the boron surface density. Especially no $\{100\}$ face is observed by TEM.

Anisotropic structures within isotropic nanoparticles: the case of nickel boride $\mathrm{NiB}$. In contrast to $\mathrm{YB}_{4}$ and $\mathrm{YB}_{6}$, the spherical morphology of the NiB nanoparticles is not related to the orthorhombic crystal structure (Amam). This conclusion is supported by the large density of crystalline defects (Fig. 5) that precludes any structure-driven faceting. The well-shaped spherical particles are unusual in the case of an anisotropic crystal structure, such as $\mathrm{NiB}$. Hence, this morphology suggests solidification from molten metal or alloy droplets. ${ }^{41}$ The melting point of bulk NiB is tabulated at $1035^{\circ} \mathrm{C},{ }^{4}$ close to the value for bulk gold. As known for gold ${ }^{42}$ and covalent solids, ${ }^{43}$ strong melting point depression can occur in this size range. Although physical data are missing in the case of $\mathrm{NiB}$ to evaluate the expected melting point of $10 \mathrm{~nm} \mathrm{NiB}$ nanoparticles, one can point out that the synthesis temperature of $750^{\circ} \mathrm{C}$ lies in the range where melting can be expected for $10 \mathrm{~nm}$ nanoparticles of metalliccovalent cohesion. ${ }^{42,43}$ Following the assumption of $\mathrm{NiB}$ crystallization from molten droplets and considering the very high melting point of boron allotropes, ${ }^{4}$ then the droplets should be confined within the solid amorphous boron matrix. Solidification and crystallization within the confined droplets could explain the high density of crystal defects observed within the $\mathrm{NiB}$ nanoparticles after cooling. On the contrary, $\mathrm{YB}_{4}$ and $\mathrm{YB}_{6}$ exhibit melting points higher than $2300{ }^{\circ} \mathrm{C}$, which precludes any process involving a molten $\mathrm{Y}-\mathrm{B}$ alloy. Hence, the growth mechanism follows a more conventional route that yields to faceting according to relative facet energies and the Wulff Law. 


\section{Experimental}

\section{Syntheses}

The precursors $\mathrm{NaBH}_{4}$ (min $98 \%$, Alfa Aesar), anhydrous $\mathrm{YCl}_{3}\left(99.99 \%\right.$, Alfa Aesar) and anhydrous $\mathrm{NiCl}_{2}$ (99.99\%, Alfa Aesar) were stored in an argon filled glovebox (M-Braun) and used as received. A LiCl/ $\mathrm{KCl}$ mixture at the eutectic composition (wt. 45/55) was prepared from the commercially available salts (Aldrich). The mixture was evacuated under vacuum at $200^{\circ} \mathrm{C}$ for 1 day, and then stored in a glovebox. Powder mixtures were manipulated in an inert atmosphere. They were finely ground in a ballmill (Retsch MM400) for $2 \mathrm{~min}$ at $20 \mathrm{~Hz}$, and then transferred into a glassy carbon crucible. The crucible was maintained in a quartz tube, which was connected to an argon ramp. During heating in a vertical oven (Carbolite), the medium was stirred with a glassy carbon rod rotating at $100 \mathrm{rpm}$. After the apparatus cooled below $100^{\circ} \mathrm{C}$, the frozen salt medium was washed with deionized water, the suspension was centrifuged and the powder was separated from the supernatant. The obtained powder was then washed, centrifuged and recovered from the supernatant three times. The powder was evacuated at $40^{\circ} \mathrm{C}$ overnight.

Nickel boride syntheses. Following the general procedure, $2.5 \mathrm{~g}$ of eutectic mixture were mixed to $2.0 \mathrm{mmol}$ of nickel (II) chloride and 4.0, 2.4, 2.0 and $1.3 \mathrm{mmol}$ of sodium borohydride for experiments 1:2, 1:1.2, $1: 1$ and 1:0.65 respectively. The mixture was heated from ambient temperature to $750^{\circ} \mathrm{C}$ $\left(20^{\circ} \mathrm{C} \cdot \mathrm{min}^{-1}\right)$, then maintained at $750{ }^{\circ} \mathrm{C}$ for $1.5 \mathrm{~h}$ before cooling.

Yttrium boride syntheses. Each synthesis is named after the molar ratio of inserted precursors, the temperature and the dwell time. The parameters of the yttrium borides syntheses are detailed in Table S1.

\section{Techniques}

Powder X-ray diffraction (XRD). XRD measurements were performed on a D8 Bruker apparatus operating at the $\mathrm{Cu}-\mathrm{K} \alpha 1$ radiation. Patterns were indexed according to ICDD files: $\mathrm{NiB}$ (01-074-1207), $\mathrm{Ni}_{4} \mathrm{~B}_{3}$ (01-0732551), $\mathrm{Ni}_{2} \mathrm{~B}$ (04-001-0967), $\mathrm{Ni}_{3} \mathrm{~B}$ (04-014-0853), $\mathrm{YB}_{6}$ (04-003-0596), $\mathrm{YB}_{4}$ (00-007-0057), $\mathrm{YBO}_{3}$ (01-0893501), $\mathrm{Y}_{2} \mathrm{O}_{3}$ (01-071-0049). Apparent crystallite sizes $\varepsilon$ were calculated using the Scherrer formula and pseudo-Voigt functions to fit peaks.

Transmission electron microscopy (TEM). A 120 kV Tecnai Spirit microscope was used for TEM and Selected Area Electron Diffraction (SAED) pictures. High Resolution-TEM (HRTEM) was also operated on a $200 \mathrm{kV}$ JEOL JEM 2011 apparatus, at the Institut des Matériaux de Paris Centre. Samples were prepared by evaporating a drop of suspension in ethanol on a carbon-coated copper grid.

Energy Dispersive X-Ray Spectrometry (EDX). Elemental EDX analyses were obtained on a Scanning Electron Microscope (SEM) S-3400-N (Hitachi), equipped with an EDX detector (Oxford) calibrated prior measurements to allow for retrieving quantitative data. $100 \times 50 \mu \mathrm{m}^{2}$ areas were probed. Acceleration tension of the source was $10 \mathrm{kV}$. A titanium grid was used as quantitative reference. Samples were fixed to a conductive carbon scotch.

Nitrogen sorption. Samples were degassed at $150{ }^{\circ} \mathrm{C}$ overnight before measuring on an ASAP 2000 apparatus (Micromeritics).

\section{Conclusions}

To conclude, this study shows for the first time that the stoichiometry of metal boride nanocrystals can be tuned. To achieve this goal, syntheses are performed in inorganic molten salts that are stable in temperature, with negligible vapor pressure, thus ensuring a convenient, low cost and scalable method. Single crystalline phases can be isolated in most $\mathrm{Ni}-\mathrm{B}$ systems and in $\mathrm{YB}_{6}$, although $\mathrm{NiB}$ is obtained with slight amounts of $\mathrm{Ni}_{4} \mathrm{~B}_{3}$ as side-product, while $\mathrm{YB}_{4}$ could not be isolated properly. Besides, the crystalline metal borides are always obtained along with amorphous boron, which in some cases (e.g. NiB) play an important role on the particle shape and size. This points out different crystallization mechanisms, which might depend on the melting point of the nanoscaled alloys. When the synthesis temperature is lower than the melting point (e.g. the Y-B system), then classical particle growth may occur, then leading to 
faceting and anisotropic shapes expected from the Wulff Law, without any surface-directing ligand. On the opposite, if the synthesis is performed at a temperature exceeding the melting point, then amorphous boron may act as a template confining alloy droplets, which would in turn crystallize upon cooling in the space defined by the droplets, thus yielding metal boride spheres. In the case of an anisotropic crystal structure (e.g. NiB), the competition between the structure-driven tendency to anisotropic growth and the spherical shape imposed by the template results in strains, released in the form of uniaxial crystal defects. To confirm these mechanistic conclusions, in situ characterizations are under way, by using spectroscopic, scattering and electron microscopy techniques.

\section{References}

1 N. N. Greenwood, R. V. Parish and P. Thornton, Q. Rev., 1965, 441-464.

2 Q. Gu, G. Krauss and W. Steurer, Adv. Mater., 2008, 20, 3620-3626.

3 W. G. Fahrenholtz, G. E. Hilmas, I. G. Talmy and J. a. Zaykoski, J. Am. Ceram. Soc., 2007, 90, 1347-1364.

D. R. Lide, Ed., CRC Handbook of Chemistry and Physics, 88th Edition, CRC Press/Taylor \& Francis Group, Boca Raton, FL, 2007.

S. Rades, S. Kraemer, R. Seshadri and B. Albert, Chem. Mater., 2014, 26, 1549-1552.

Y.-C. Liu and Y.-W. Chen, Ind. Eng. Chem. Res., 2006, 45, 2973-2980.

C. Wu, F. Wu, Y. Bai, B. Yi and H. Zhang, Mater. Lett., 2005, 59, 1748-1751.

N. Patel, R. Fernandes, G. Guella, A. Kale, A. Miotello, B. Patton and C. Zanchetta, J. Phys. Chem. C, 2008, 112, 6968-6976.

U. B. Demirci and P. Miele, Phys. Chem. Chem. Phys., 2010, 12, 14651-65.

L. Chen, Y. Lu, Q. Hong, J. Lin and F. M. Dautzenberg, Appl. Catal. A Gen., 2005, 292, $295-304$.

J. Xu and M. Saeys, J. Catal., 2006, 242, 217-226.

M. Saeys, K. F. Tan, J. Chang and A. Borgna, Ind. Eng. Chem. Res., 2010, 49, 11098-11100.

X. H. Ji, Q. Y. Zhang, J. Q. Xu and Y. M. Zhao, Prog. Solid State Chem., 2011, 39, 51-69.

M. Takeda, M. Terui, N. Takahashi and N. Ueda, J. Solid State Chem., 2006, 179, 2823-2826.

T. Mori and T. Tanaka, J. Solid State Chem., 2006, 179, 2889-2894.

J. Nagamatsu, N. Nakagawa, T. Muranaka, Y. Zenitani and J. Akimitsu, Nature, 2001, 410, 63-4.

C. Buzea and T. Yamashita, Supercond. Sci. Technol., 2001, 14, R115-R146.

J. Bardeen, L. N. Cooper and J. R. Schrieffer, Phys. Rev., 1957, 108, 1175-1204.

J. Kortus, I. Mazin, K. Belashchenko, V. Antropov and L. Boyer, Phys. Rev. Lett., 2001, 86, 4656-4659.

L. M. Liz-Marzán, C. J. Murphy and J. Wang, Chem. Soc. Rev., 2014, 43, 3820-2.

G. L. Nealon, B. Donnio, R. Greget, J.-P. Kappler, E. Terazzi and J.-L. Gallani, Nanoscale, 2012, 4, 5244-58.

C. Goldmann, R. Lazzari, X. Paquez, C. Boissière, F. Ribot, C. Sanchez, C. Chanéac and D. Portehault, ACS Nano, 2015.

D. V. Talapin, J. S. Lee, M. V. Kovalenko and E. V. Shevchenko, Chem. Rev., 2010, 110, 389-458.

S. Carenco, D. Portehault, C. Boissière, N. Mézailles and C. Sanchez, Chem. Rev., 2013, 113, 7981-8065.

J. R. Brewer, R. M. Jacobberger, D. R. Diercks and C. L. Cheung, Chem. Mater., 2011, 23, 2606-2610.

S. S. Amin, S. Li, J. R. Roth and T. T. Xu, Chem. Mater., 2009, 763-770.

R. K. Selvan, I. Genish, I. Perelshtein, J. M. Calderon Moreno and A. Gedanken, J. Phys. Chem. C, $2008,112,1795-1802$.

Y. Liu, W. Lu, J. Qin and D. Zhang, J. Alloys Compd., 2007, 431, 337-341.

M. Zhang, Y. Jia, G. Xu, P. Wang, X. Wang, S. Xiong, X. Wang and Y. Qian, Eur. J. Inorg. Chem., 2010, 2010, 1289-1294.

L. Shi, Y. Gu, L. Chen, Z. Yang, J. Ma and Y. Qian, Mater. Lett., 2004, 58, 2890-2892.

P. Cai, H. Wang, L. Liu and L. Zhang, J. Ceram. Soc. Japan, 2010, 118, 1102-1104.

W. N. Kang, E.-M. Choi, H.-J. Kim, H.-J. Kim and S.-I. Lee, Phys. C Supercond., 2003, 385, 24-30.

S. Lai, S. Liu and M. Lan, J. Cryst. Growth, 2007, 304, 460-463.

S.-M. Zhou, P. Wang, S. Li, B. Zhang, H.-C. Gong and X.-T. Zhang, Mater. Lett., 2009, 63, 1680-1682.

D. Portehault, S. Devi, P. Beaunier, C. Gervais, C. Giordano, C. Sanchez and M. Antonietti, Angew. Chem. Int. Ed., 2011, 50, 32623265.

36 Z. L. Schaefer, X. Ke, P. Schiffer and R. E. Schaak, J. Phys. Chem. C, 2008, 112, 19846-19851.

37 B. Albert and H. Hillebrecht, Angew. Chem. Int. Ed., 2009, 48, 8640-8668.

38 H. Cölfen and M. Antonietti, Mesocrystals and Non-classical Crystallization, Wiley, San Francisco, CA, 2008.

39 B. Albert, Eur. J. Inorg. Chem., 2000, 2000, 1679-1685.

40 S. Otani, Y. Xuan, Y. Yajima and T. Mori, J. Alloys Compd., 2003, 361, L1-L3.

41 T.-H.-C. Chan-Chang, G. Gouget, C. Sanchez, S. Carenco and D. Portehault, In prep.

42 P. Buffat and J. P. Borel, Phys. Rev. A, 1976, 13, 2287-2298.

43 H. H. Farrell and C. D. Van Siclen, J. Vac. Sci. Technol. B Microelectron. Nanom. Struct., $2007,25,1441$. 


\section{New route toward nanosized crystalline metal borides with tuneable stoichiometry and variable morphologies}

G. Gouget, ${ }^{a}$ P. Beaunier, ${ }^{\mathrm{b}}$ David Portehault ${ }^{\mathrm{a},{ }^{*}}$ and Clément Sanchez ${ }^{\mathrm{a}}$

\section{Supplementary information}

Table S1 Reaction conditions for the synthesis of yttrium borides.

Fig. S1 Low magnification TEM picture of the sample obtained with initial ratio $\mathrm{NiCl}_{2}: \mathrm{NaBH}_{4}=1: 2$.

Fig. S2 HRTEM pictures of $\mathrm{NiB}$ nanoparticles obtained with initial ratio $\mathrm{NiCl}_{2}: \mathrm{NaBH}_{4}=1: 2$.

Fig. S3 HRTEM picture of $\mathrm{Ni}_{4} \mathrm{~B}_{3} 30 \mathrm{~nm}$ particle, minor product in the sample obtained with initial ratio $\mathrm{NiCl}_{2}: \mathrm{NaBH}_{4}=1: 2$.

Fig. S4 TEM pictures of $\mathrm{Ni}_{4} \mathrm{~B}_{3}$ and $\mathrm{Ni}_{2} \mathrm{~B}$ particles, obtained for initial ratios $\mathrm{NiCl} 2: \mathrm{NaBH}_{4}=1: 1.2$ and 1:1, respectively.

Fig. S5 TEM picture of $\mathrm{Ni}_{3} \mathrm{~B}$ particles obtained for an initial ratio $\mathrm{NiCl}_{2}: \mathrm{NaBH}_{4}=1: 0.65$.

Fig. S6 EDX spectra of samples $\mathrm{NiB}, \mathrm{Ni}_{4} \mathrm{~B}_{3}, \mathrm{Ni}_{2} \mathrm{~B}$ and $\mathrm{Ni}_{3} \mathrm{~B}$.

Table $\mathbf{S 1}$ Reaction conditions for the synthesis of yttrium borides. $\mathrm{YCl}_{3}: \mathrm{NaBH}_{4}$ is the yttrium-to-boron source molar ratio, $T$ and $t$ are the temperature and dwell time, respectively. The corresponding masses are reported for each synthesis. 


\begin{tabular}{cccccc}
\hline $\mathrm{YCl}_{3}: \mathrm{NaBH}_{4}$ & $\begin{array}{c}\mathrm{T} \\
\left({ }^{\circ} \mathrm{C}\right)\end{array}$ & $\begin{array}{c}\mathrm{t} \\
(\mathrm{h})\end{array}$ & $\begin{array}{c}\mathrm{YCl}_{3} \\
(\mathrm{mg})\end{array}$ & $\begin{array}{c}\mathrm{NaBH}_{4} \\
(\mathrm{mg})\end{array}$ & $\begin{array}{c}\mathrm{LiCl} / \mathrm{KCl} \\
(\mathrm{g})\end{array}$ \\
\hline $\mathbf{1 : 1 2}$ & $\mathbf{1 0 0 0}$ & $\mathbf{4}$ & $\mathbf{9 8}$ & $\mathbf{2 2 7}$ & $\mathbf{1 , 2 5}$ \\
$\mathbf{1 : 8}$ & $\mathbf{9 0 0}$ & $\mathbf{4}$ & $\mathbf{1 9 5}$ & $\mathbf{3 0 3}$ & $\mathbf{2 , 5 0}$ \\
$1: 8$ & 900 & 1 & 195 & 303 & 2,50 \\
$1: 8$ & 900 & 0.5 & 195 & 303 & 2,50 \\
$1: 8$ & 800 & 4 & 195 & 303 & 2,50 \\
$1: 8$ & 800 & 1 & 195 & 303 & 2,50 \\
$1: 8$ & 800 & 0.5 & 195 & 303 & 2,50 \\
$1: 8$ & 700 & 4 & 195 & 303 & 2,50 \\
$1: 5$ & 900 & 4 & 195 & 189 & 2,50 \\
$1: 5$ & 900 & 1 & 195 & 189 & 2,50 \\
$1: 5$ & 900 & 0.5 & 195 & 189 & 2,50 \\
$1: 5$ & 800 & 4 & 195 & 189 & 2,50 \\
$1: 5$ & 800 & 2 & 195 & 189 & 2,50 \\
$\mathbf{1 : 5}$ & $\mathbf{8 0 0}$ & $\mathbf{1}$ & $\mathbf{1 9 5}$ & $\mathbf{1 8 9}$ & $\mathbf{2 , 5 0}$ \\
$1: 5$ & 800 & 0.5 & 195 & 189 & 2,50 \\
$1: 5$ & 700 & 4 & 195 & 189 & 2,50 \\
\hline
\end{tabular}

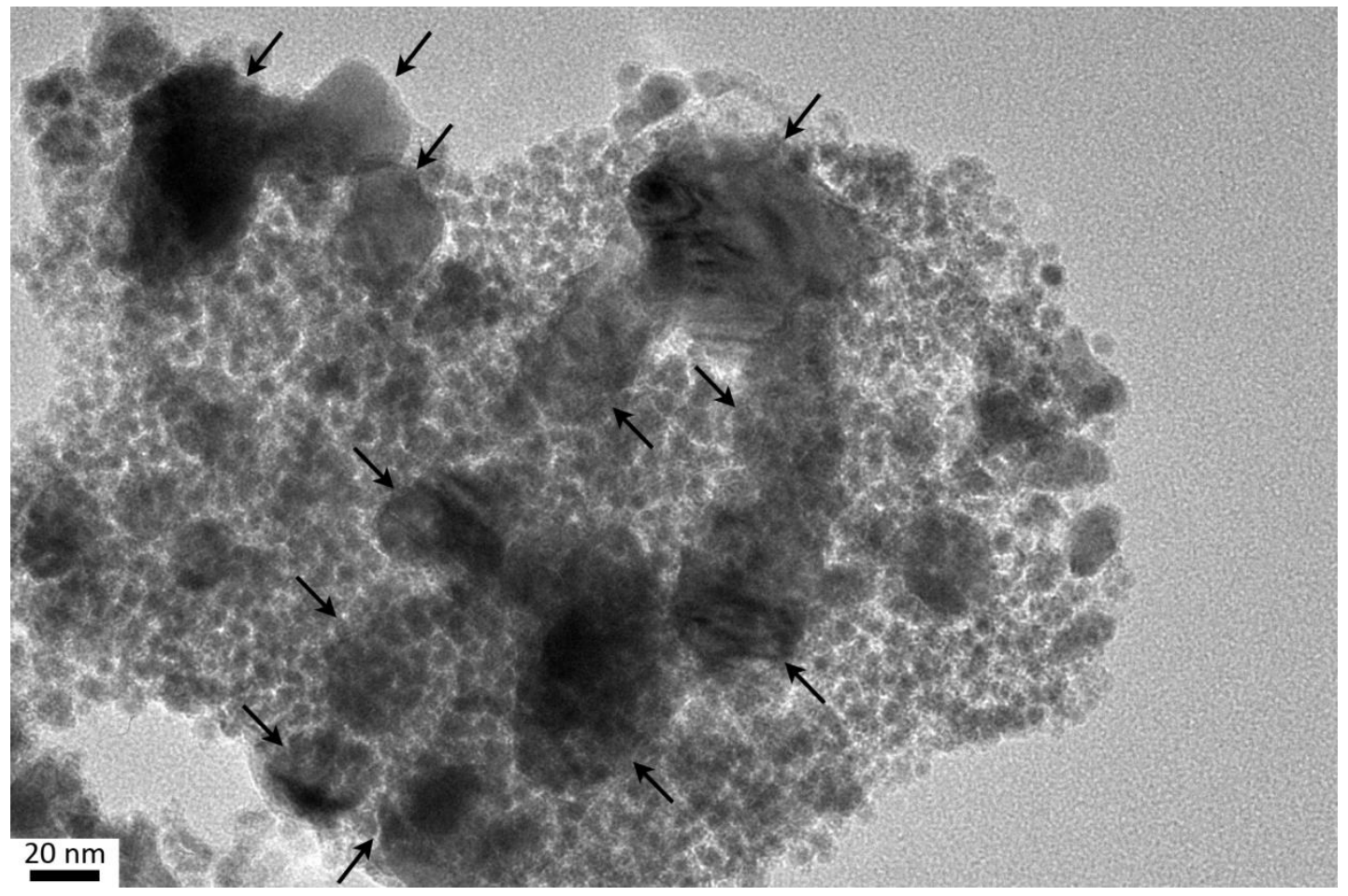

Fig. S1 TEM picture of the sample obtained with initial ratio $\mathrm{NiCl}_{2}: \mathrm{NaBH}_{4}=1: 2$. The sample is composed of crystalline particles dispersed in an amorphous boron phase. The particles can be divided in two groups, depending on size and morphology: the major one is composed of particles around $5 \mathrm{~nm}$ in diameter, with a spherical morphology, that are NiB particles according to HRTEM (Fig. S2 and Fig. 3). Other particles in minority exhibit diameters above $20 \mathrm{~nm}$ (black arrows) and are slightly faceted. They are indexed on the $\mathrm{Ni}_{4} \mathrm{~B}_{3}$ structure. (Fig. S3). 


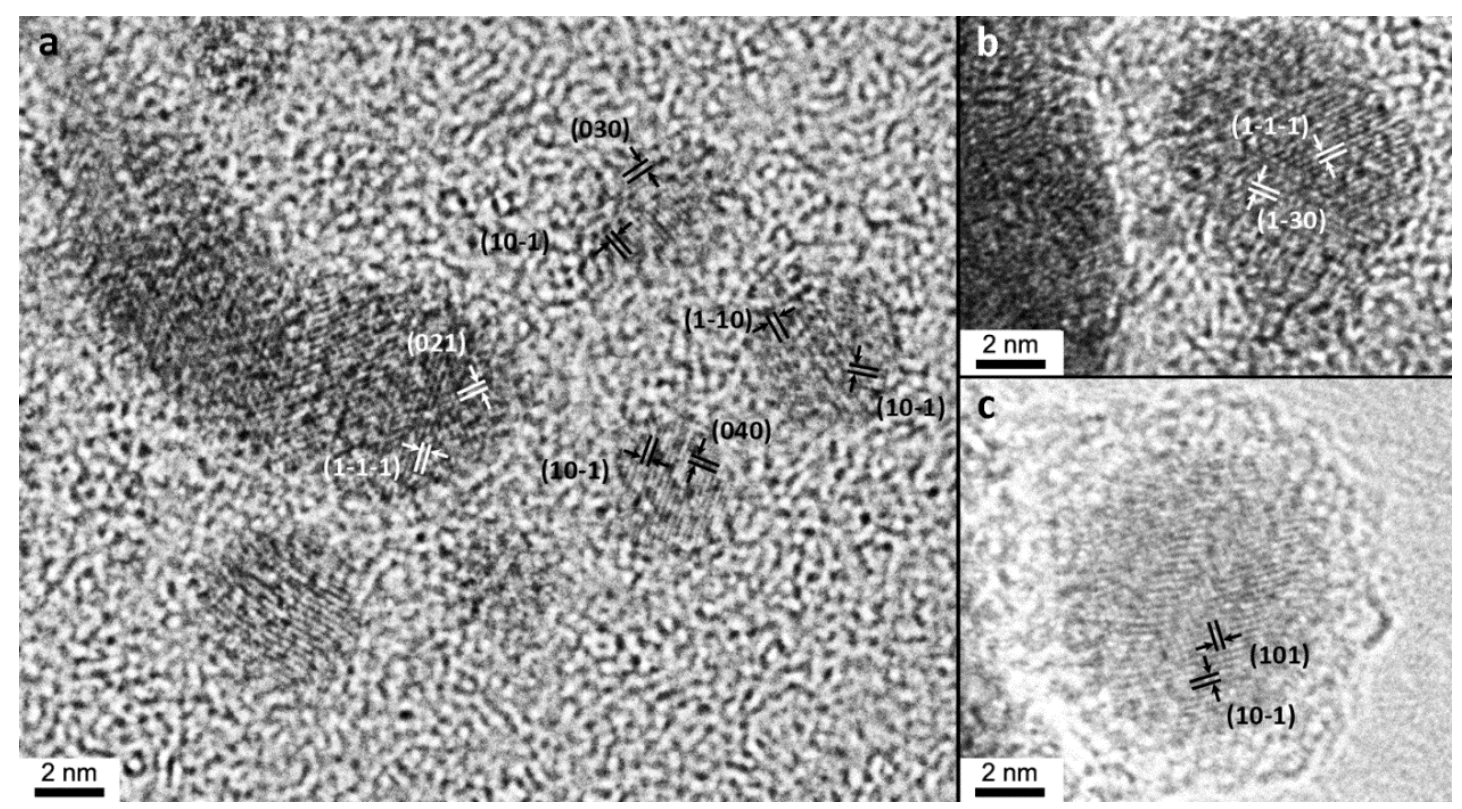

Fig. S2 HRTEM pictures of $\mathrm{NiB}$ nanoparticles obtained with initial ratio $\mathrm{NiCl}_{2}: \mathrm{NaBH}_{4}=1: 2$. Spherical particles 2 to $6 \mathrm{~nm}$ in diameter are indexed along the NiB structure. Some crystal defects are observed in the particles. c) The crystalline spheres are surrounded by a ca. $1.5 \mathrm{~nm}$ thick amorphous shell.

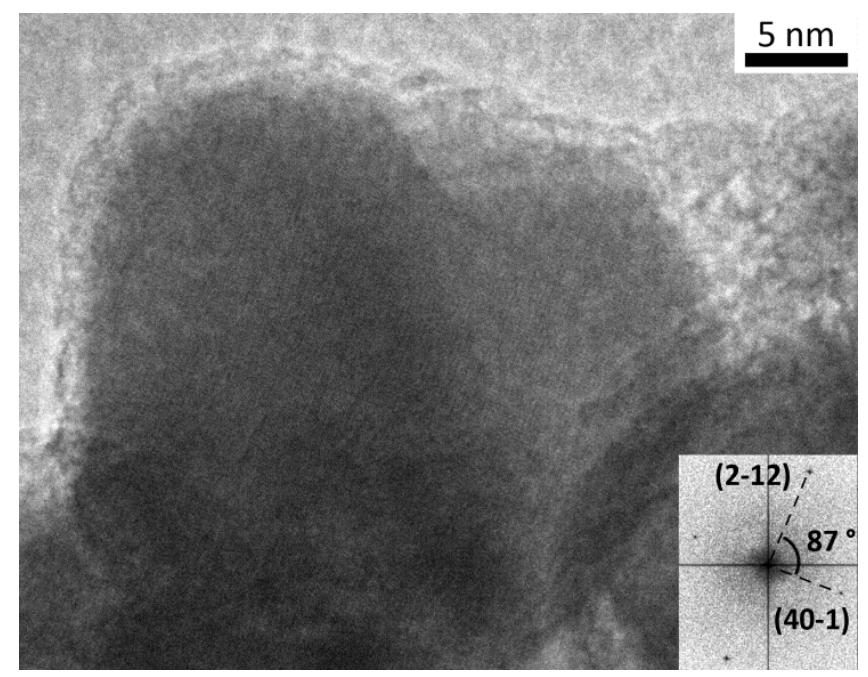

Fig. S3 HRTEM picture of a $30 \mathrm{~nm}$ particles, minor product in the sample obtained with initial ratio $\mathrm{NiCl}_{2}: \mathrm{NaBH}_{4}=1: 2$. The inset shows the corresponding Fourier transform indexed on the $\mathrm{Ni}_{4} \mathrm{~B}_{3}$ structure. 


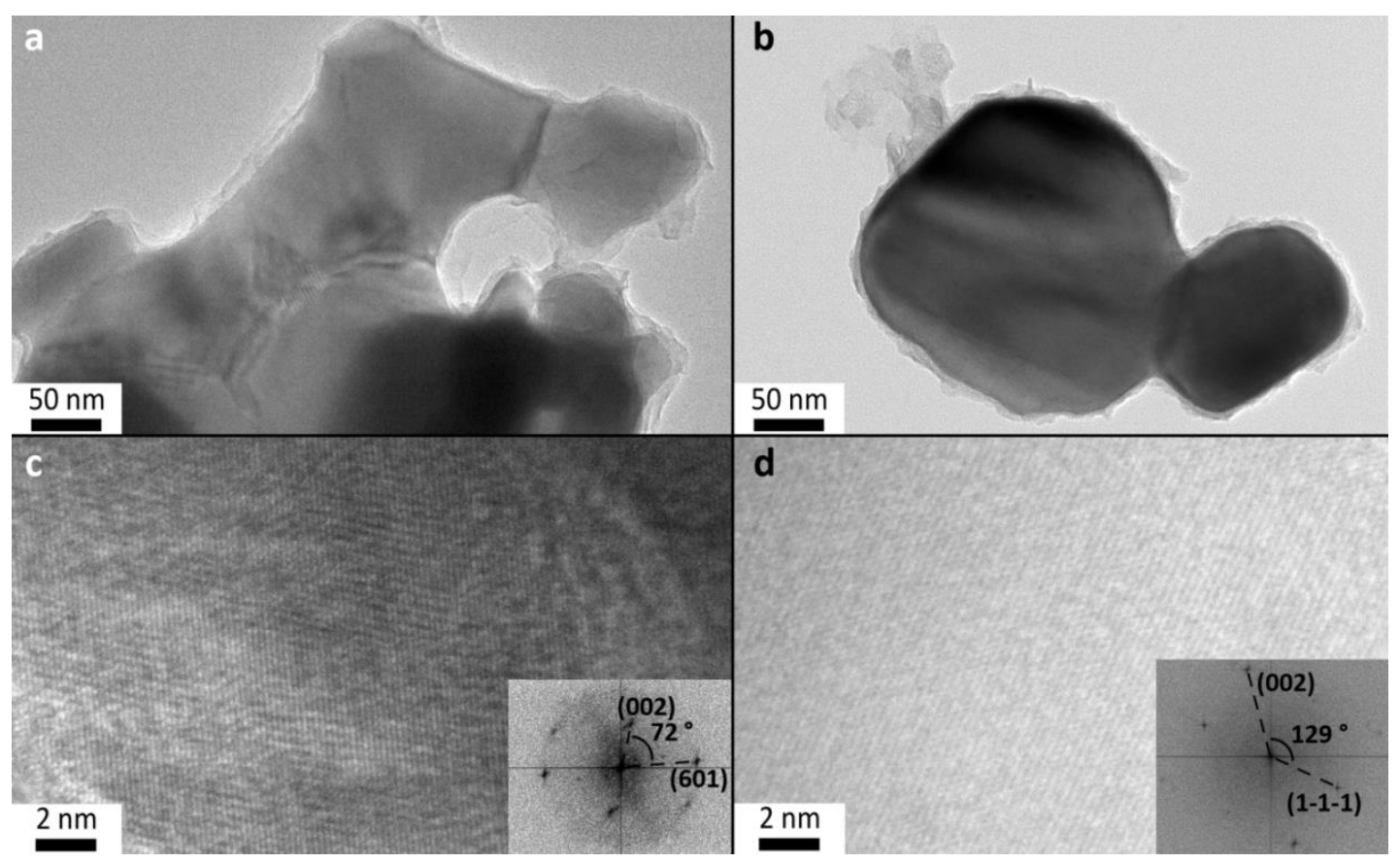

Fig. S4 TEM pictures of (a) $\mathrm{Ni}_{4} \mathrm{~B}_{3}$ and (b) $\mathrm{Ni}_{2} \mathrm{~B}$ particles, obtained for initial ratios $\mathrm{NiCl}_{2}: \mathrm{NaBH}_{4}=1: 1.2$ and 1:1, respectively. The particles are faceted and exhibit diameters between $50 \mathrm{~nm}$ and $200 \mathrm{~nm}$. They form dense aggregates and show evidences of sintering with clear grain boundaries. They are embedded in an amorphous shell that crystallizes under the electron beam, possibly related to nickel hydroxide. HRTEM pictures and corresponding Fourier transforms (insets) highlight the crystal structures of c) $\mathrm{Ni}_{4} \mathrm{~B}_{3}$ for $\mathrm{NiCl}_{2}: \mathrm{NaBH}_{4}=1: 1.2$ and of b) $\mathrm{Ni}_{2} \mathrm{~B}$ for $\mathrm{NiCl}_{2}: \mathrm{NaBH}_{4}=1: 1$.

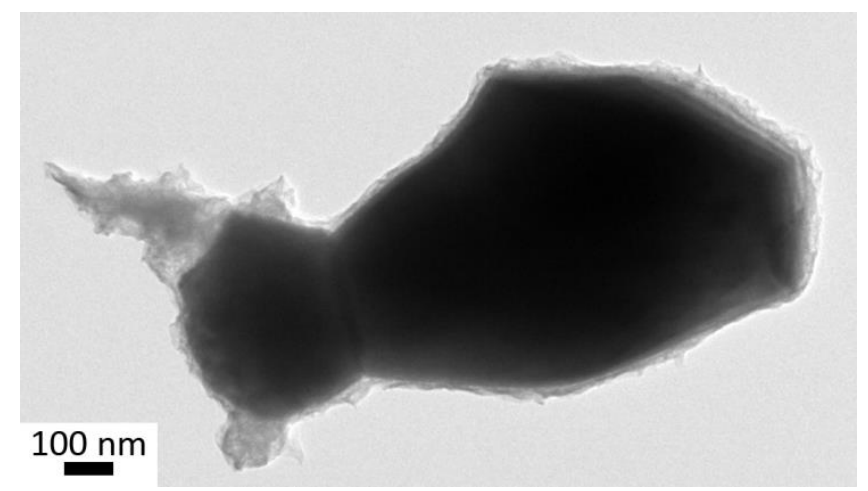

Fig. S5 TEM picture of $\mathrm{Ni}_{3} \mathrm{~B}$ particles obtained for an initial ratio $\mathrm{NiCl}_{2}: \mathrm{NaBH}_{4}=1: 0.65$. 


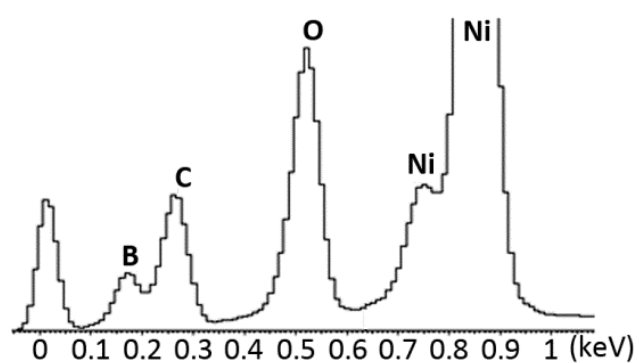

$1: 2$

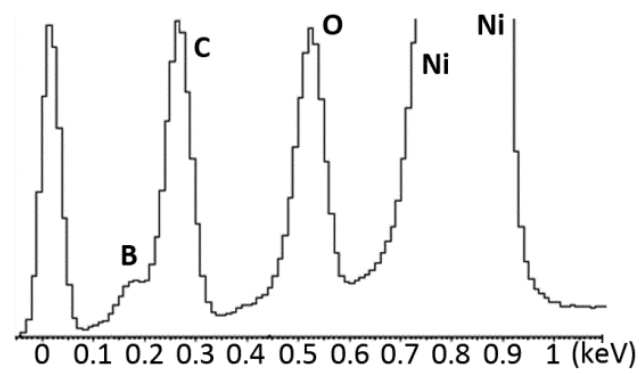

$1: 1$

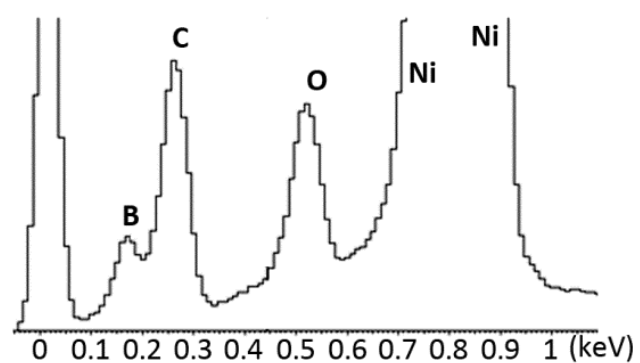

$1: 1.2$

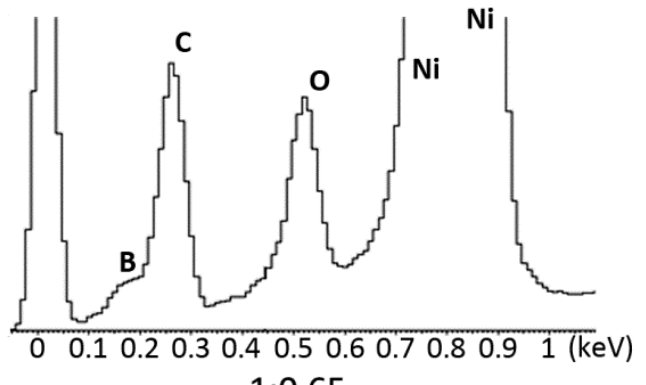

$1: 0.65$

Fig. S6 EDX spectra of samples $\mathrm{NiB}, \mathrm{Ni}_{4} \mathrm{~B}_{3}, \mathrm{Ni}_{2} \mathrm{~B}$ and $\mathrm{Ni}{ }_{3} \mathrm{~B}$, obtained with initial ratios $\mathrm{NiCl}_{2}: \mathrm{NaBH}_{4}=1: 2,1: 1.2,1: 1$ and 1:0.65, respectively. 